\title{
THE VALUE OF LARGE SCALE TOURISM IN SAMOA
}

\author{
BY \\ DONALD DONGSIK PARK
}

\author{
A thesis submitted to Victoria University of Wellington \\ in fulfilment of the requirements for the degree of \\ Masters in Development Studies
}

Victoria University of Wellington

2013 


\section{Table of Contents}

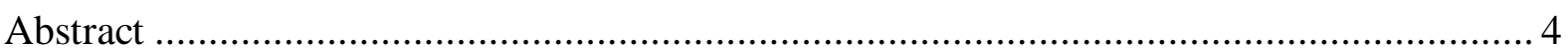

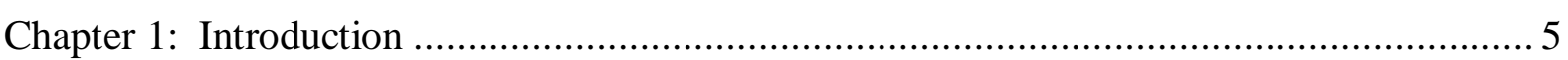

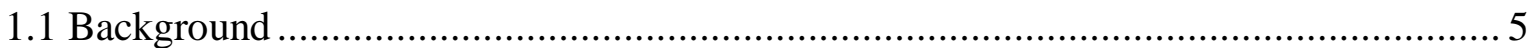

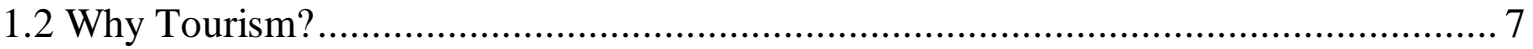

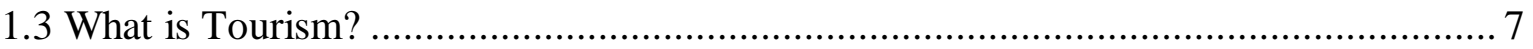

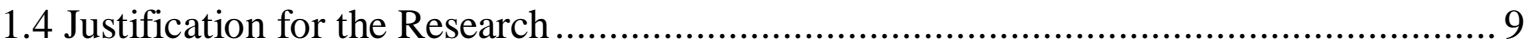

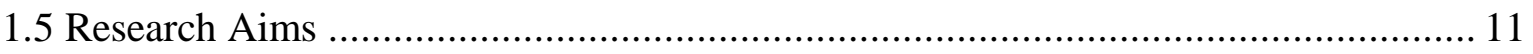

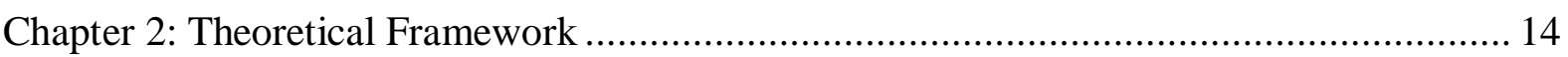

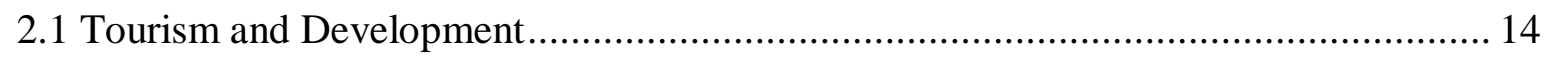

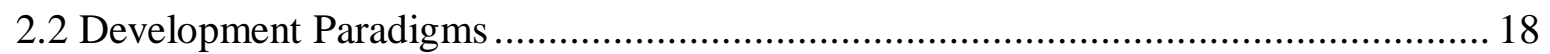

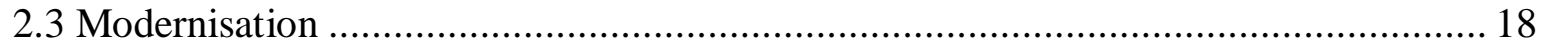

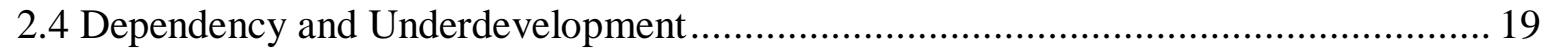

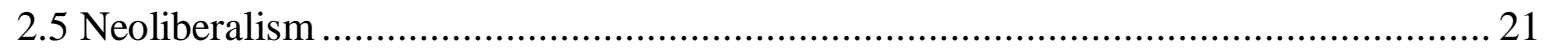

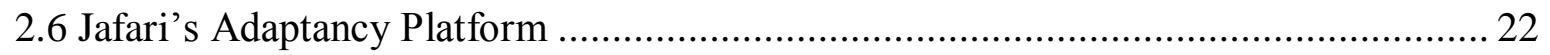

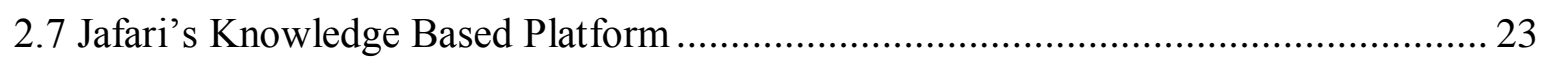

2.8 Leakages and the Multiplier Effect ......................................................................... 24

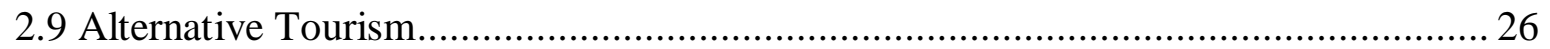

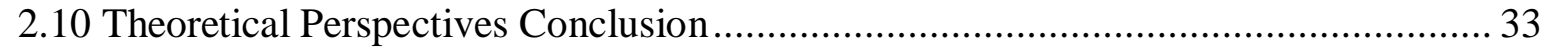

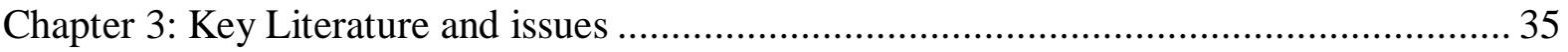

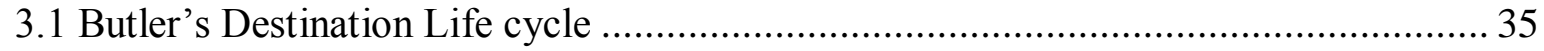

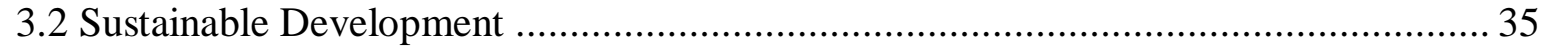

3.3 Practical Strategies for Sustainable Development in Mass Tourism ......................... 36

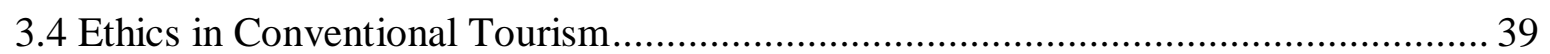

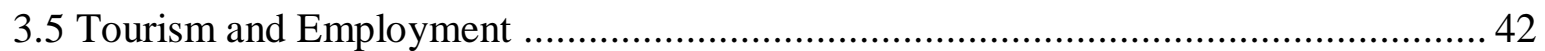

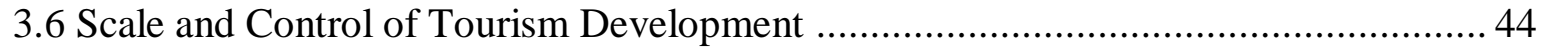

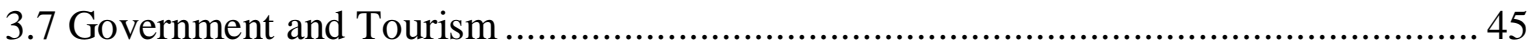

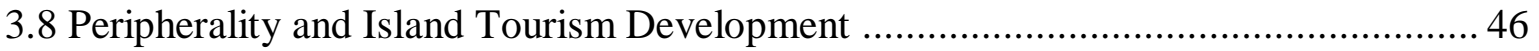

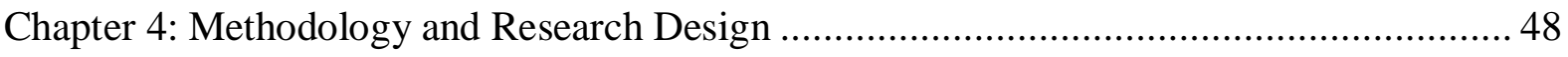

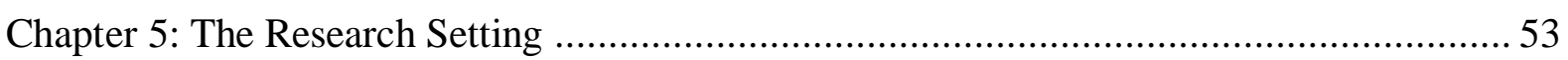

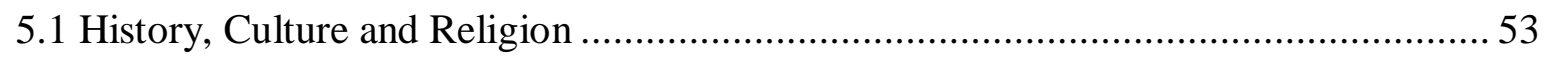

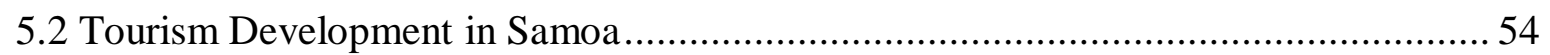

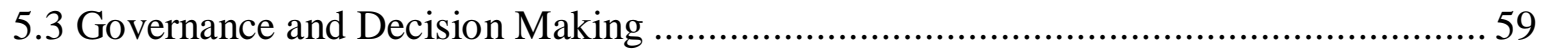

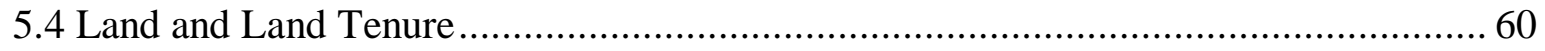

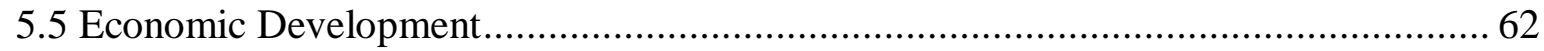




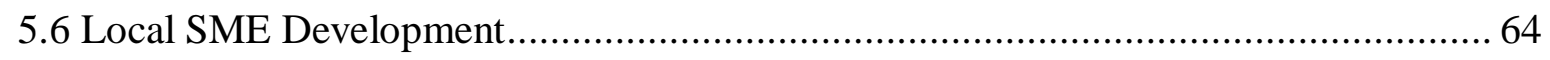

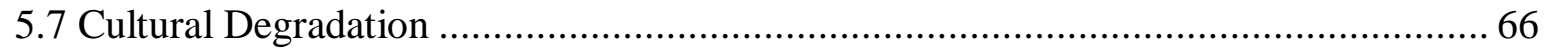

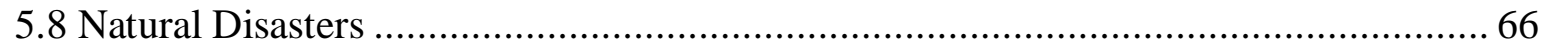

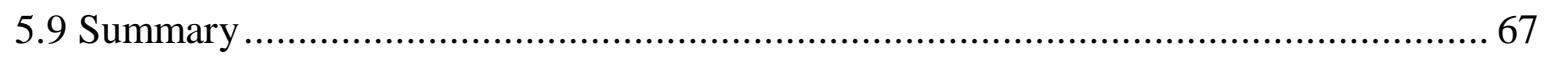

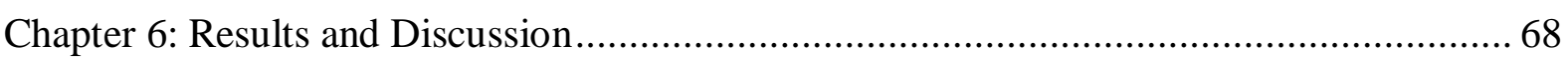

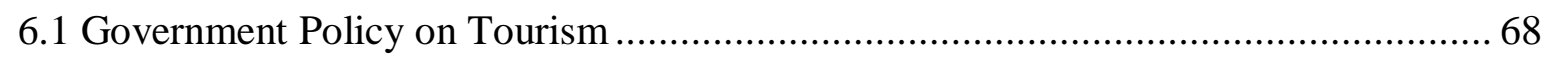

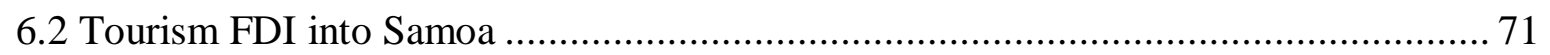

6.3 Ministry of Women, Community and Social Development ...................................... 73

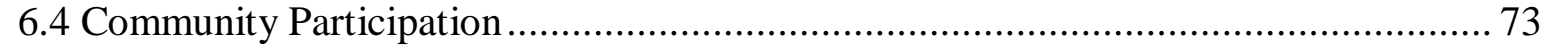

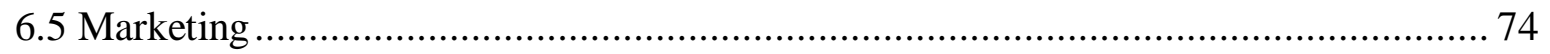

6.6 Case Study: Aggie Grey's Lagoon and Resort ..................................................... 76

6.7 Samoa Tourism Development Plan 2009 - 2013 ............................................... 78

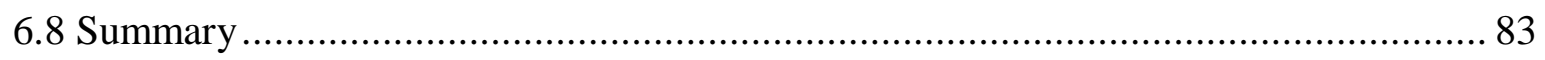

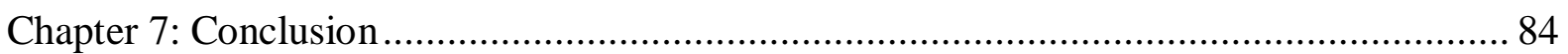

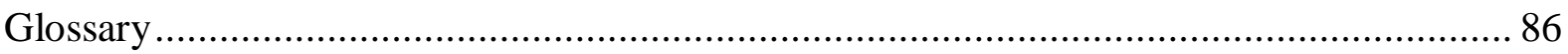

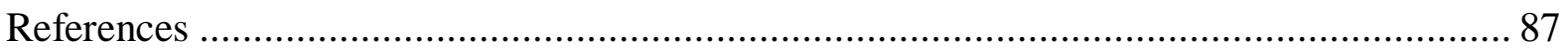

Appendix: Information Sheet, Questionnaire and Map of Samoa ............................... 94

The Value of Large Scale Tourism Ventures in Samoa .................................................. 95

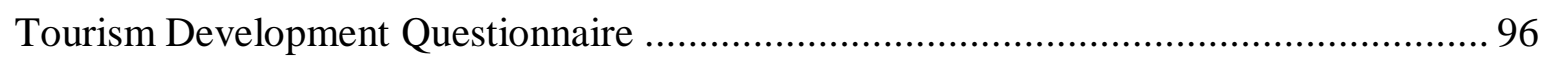

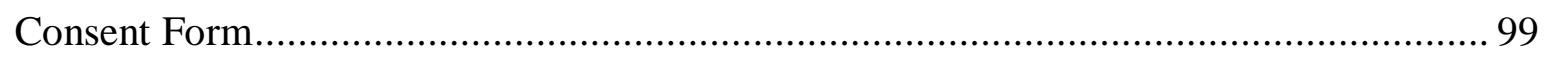

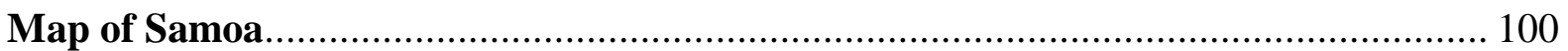




\begin{abstract}
During the mid to late seventies serious questions were raised regarding the value of mass tourism. This lead to the creation of the alternative development paradigm with its preference towards small scale, local and community based and controlled projects which have gained wide acceptance within the field of development studies. This research looks to reopen and examine the case against mass tourism as a development tool under the following arguments:

- The initial assessment was done in the late seventies and a combination of changes in business practices and consumer demands for ethical behaviour has potentially changed the development outcomes for host nations

- Governments have a greater and more balanced awareness of the range of development issues and enterprises need to respond to this

- Alternative development suffers from similar criticisms to those that have been directed at mass tourism as well as some unique issues

- Labour force training has been largely overlooked as critical step in maximising potential development outcomes for host nations

- Two major critiques around power inequality (Britton 1983) and empowerment (Sofield 2003) are external subjective judgements about development outcomes where feedback and conclusions from within host populations might add additional insight.
\end{abstract}

A survey questioning the impact a large scale development had on people's lives was central to the research. However, due to difficulties getting survey data from a large scale development in Samoa the research has focused on providing the arguments above from literature and on secondary research aims of seeking the governments views and strategies to deal with tourism and linking these strategies back to literature. 


\section{Chapter 1: Introduction}

The purpose of this initial chapter is to provide a definition of, give some background to and to introduce some characteristics regarding the nature of tourism. It will give a brief introduction to why tourism is commonly pursued and then provide the justification for the work and research objectives.

\subsection{Background}

Tourism is the largest industry in the world and has become a popular global leisure activity (World Travel and Tourism Council, 2011). In 2007, there were over 903 million international tourist arrivals, with a growth of $6.6 \%$ as compared to 2006. International tourist receipts were USD \$856 billion in 2007 (UNWTO, 2008). The World Travel and Tourism Council (WTTC) 2005 states that the industry employs over 765 million people worldwide. While the majority of this share belongs to Europe and the Americas, tourism also plays a significant proportion of many third world counties' economies. Tourism is a significant sector in 11 of the 12 countries that contain $80 \%$ of the world's poor (UNWTO 1998). Tourism has long been identified as a tool for development by boosting foreign exchange, employment and generating income including in rural areas (Clancy 1999). The relative value of tourism in proportion to total gross domestic product (GDP) in least developed countries (LDCs) is about double that of developed countries (World Travel and Tourism Council, 2005). Given this magnitude and relative importance of the industry, there is undoubtedly strong potential for development and poverty alleviation.

Through to the late 1970's it was generally accepted that more tourism and mass tourism in particular, equated to more development using a linear paradigm of development where LDCs move from their status quo towards the western style of industrialised nations. From the late 1970's onwards, as it became apparent that many countries were not achieving 
their intended development outcomes. Development literature is now littered with examples where tourism has either failed to deliver the intended benefits or worse, has had significant negative side effects. Frequent criticisms include the lack of local participation, monopolisation of the industry by multinational corporations and the lack of empowerment, local control and ownership.

This has left the current prevailing paradigm in development tourism towards alternative, small scale and local projects. Yet it is perhaps opportune to re-examine large scale mass tourism for its potential benefits and advantages may have been underestimated. This study uses the following main themes to re-examine the case on mass tourism.

- The initial assessment was done in the late seventies and a combination of changes in business practices and consumer demands for ethical behaviour has potentially changed development outcomes for host nations.

- Governments have a greater, more balanced awareness of the range of development issues and enterprises need to respond to this.

- Alternative development suffers from similar criticisms that have been directed at mass tourism as well as their own unique issues.

- Labour force and entrepreneurial training has been largely overlooked as critical step in maximising potential development outcomes for host nations

- Two major critiques around power inequality (Britton 1983) and empowerment (Sofield 2003) are external subjective judgements about development outcomes where feedback and conclusions from within host populations would perhaps add additional insight. 


\subsection{Why Tourism?}

The most compelling reason for pursuing tourism as a development strategy is its alleged positive contribution to the local or national economy (Sharpley \& Telfer 2002). For many developing countries with a limited industrial sector, few natural resources and a dependence on international aid, there simply is not any other realistic development option for the creation of employment, foreign exchange and investment (Brown 1998). This is certainly the case in Samoa where remittances account for $24 \%$ of GDP (U.S. Department of State, 2011). Elsewhere, Sharpley and Telfer (2003) present the case of Gambia, where up to ten villagers are supported by the one tourism job, demonstrating the potential for tourism to generate employment and promote development.

Tourism is also seen as an effective means of redistributing wealth and investment from developed nations to less developed nations or from more developed regions to less developed. Developed countries are in principle supporting the growth of less developed countries by investing in tourism and through tourist remittances in destination areas. Sharpley and Telfer (2003) point out that tourism is unique in that it does not normally suffer from the imposition of trade barriers which are often applied to physical goods and other types of services. In addition many of the attractions of a destination lie in the natural resources suggesting economic income from resources which come free to the host country. In comparison to other industries the barrier to entry from the initial capital outlay is certainly much less for tourism.

\subsection{What is Tourism?}

The World Tourism Organization (UNWTO) describes tourism as follows The supply of tourism services is characterized primarily by the cross-border movement of consumers. Tourism is also a highly "perishable" commodity, in the 
sense that unsold airline seats, hotel rooms, etc. have no residual value. The industry is highly infrastructure dependent, and relies upon various transport services to deliver clients. (UNWTO, 2008).

Sharpley and Telfer (2003, pp. 21-22) define the following characteristics of tourism

- "It is normally considered a leisure activity, generally associated with short-term escape from the routine or ordinary and implicitly involving freedom from paid and domestic work"

- "It is socially patterned; that is the ability to participate in tourism and the nature of tourism consumption is influenced by the tourists' socioeconomic background"

- "It is supported by a diverse fragmented and multisectoral industry, the structure and characteristics of which are significant determinants in the nature of tourism development"

- "It is largely dependent upon the physical, social and cultural attributes of the destination and the promise of excitement, authenticity, and the extraordinary. It is also, therefore. An ecological phenomenon inasmuch as tourism not only requires an attractive, different environment, but also interacts with and impacts upon that environment"

Butler (1990) states an incredible amount of ignorance with the dimensions of tourism citing that few people have an awareness of its true magnitude, economic and social linkages, and political significance. He considers the following issues.

- "Ignorance of the dimensions, nature and power of tourism"

- "Lack of ability to determine and appropriate level of sustainable development"

- "Lack of ability to manage tourism and control the development" 
- "Lack of appreciation that tourism has impacts, is an industry and cannot be easily reversed"

- "Lack of appreciation that tourism is dynamic and causes change as well as responding to change"

- "Lack of agreement over levels of development, over control and direction of tourism"

Even if there were a way of determining the capacity of a destination, which Butler (1990) suggests is difficult in practice, there are not any good examples of how not to exceed that capacity. Overall Butler (1990) laments that all of the above combine to create virtual anarchy for planning and coordination. The above sets the scene for the sheer breadth of issues and difficulties, which need to be considered in approaching the topic of tourism and the difficulties of implementation, planning or arriving at any clear conclusions regarding appropriate forms or levels of tourism for a particular region.

\subsection{Justification for the Research}

As the world largest industry (WTTC 2005), tourism holds great potential for the Samoa's development. Given the recent political instability in Fiji, Samoa stands to benefit from a greater number of tourists because of the relative stability of the Samoan government. Samoa is also on the cusp of World Trade Organisation membership which brings both opportunities for increased tourism as well as obligations for liberalisation.

Samoa is also on the verge of approving major tourism resort projects, which is significant in that these are the first projects where the majority of the funding and control is from offshore investors. The nature of these developments present a crossroads for Samoa in terms of change as the success of these projects potentially opens the floodgates for a 
substantial increase in project applications from other offshore investors. It is vital that Samoa proceeds in a responsible and sustainable manner as changes can be difficult to reverse. This project will attempt to discuss the tourism issues facing the country, make observations from a large scale operation in Samoa to provide guidelines based on those observations and from secondary research.

Much of the recent academic work on tourism in Samoa has tended to focus on specific projects and smaller developments predominantly at a community level and been reasonably critical of larger scale mass developments. At the end of her book Tourism for Development, Scheyvens (2002) poses the question, can mass tourism be beneficial to local communities? This research will challenge the notion of mass tourism being necessarily detrimental to development and will try to find the conditions for development and tourism with an emphasis on mass or conventional tourism. Lea (1988) suggests that people with political science backgrounds will tend to see mass tourism in particular from a dependency/underdevelopment perspective while people coming from an economics background will tend to emphasise the positive economic benefits. This paper will try to marry the two approaches to couple the power of the globalised market economy with considerations of the inequality of power, sustainability, and cultural and social issues.

Where many academics have resorted to alternative tourism, this research has deliberately placed some emphasis on mass tourism as the scale and nature of mass tourism means it has the potential to affect a society the most, both positively and negatively. Where alternative tourism can be very useful in itself and is growing at a rapid pace in a number of areas, it perhaps is lacking in scale. Butler (1992) calls alternative tourism "the thin end of the wedge" lamenting that most tourists like the convenience of mass tourism so by bypassing mass tourism a significant opportunity for foreign exchange generation is also being bypassed. 
Research has also found that it criticisms of mass tourism were also found in alternative projects (Smith \& Eadington 1992) meaning a revisit of mass tourism is perhaps timely. It was hoped the difference in approach would generate some novel insights and question the current emphasis on smaller locally based alternative solutions.

With Samoa looking to take on several foreign owned large tourism projects the above dynamics make Samoa and extremely interesting backdrop for tourism research at this time. The wider issues and global debate over tourism will take place in microcosm over the next few decades. It is hoped that this research will be of some benefit to tourism policymakers and add constructively to the lively debate on tourism and development.

\subsection{Research Aims}

This research aims to research the linkages between large scale conventional tourism and development as well as contributing to answering the question "Can large scale projects contribute to the development process?", using Samoa as a microcosm for the analysis.

Samoa is particularly interesting for two reasons. Firstly it has recommendations from its private sector to the government to limit the scale of hotels to around 150 rooms. (The two largest hotels at present are Aggie's Greys City Hotel and Aggie Grey's resort and Spa, which have 152 and 140 rooms respectively). Secondly it is at a crossroads in terms of tourism development with its current application to the UNWTO and the obligations for deregulation in tourism and other sectors which come with ascension. There is already much research surrounding the economic benefits but the gaps in the research comes from

- Examining the issues from both and economic and broader development perspective

- Much of the original research was done about 30 years ago and the environment and business practices may have changed development outcomes 
- Much of the research is based on qualitative arguments and a quantitative approach may add additional insight

- Development of employment and entrepreneurial capacity is an area which could unlock the potential of mass tourism. Cukier (2002) states 'that studies are needed which focus on tourism employment specifically empirical studies which examine the consequences of tourism for the cultures and economies of developing countries since to date very little research exists in this area.'

I chose to do my research in Samoa because, after visiting Samoa as part of a work visit in 2003 , I found the beauty of the place was astounding but the infrastructure especially in tourism, largely underdeveloped. I was immediately engaged in wanting to understand the issues around tourism and development for this country as it was my original instinctive belief that it is a tool which could provide great benefit to the nation.

I had always just assumed (like most others) that all forms of tourism, mass or otherwise would provide a net benefit to host economies and that development would just be with regards to industry development and the benefits would accrue to the host economy. As I delved into the literature on tourism, I found that a plethora of criticism against mass tourism in particular.

It was the intention of this research to question the criticism surrounding mass tourism as instinctively it seemed counter intuitive. I wanted my research to focus on the experiences of the employees of larger sized tourism ventures. The largest venture in Samoa is 154 rooms and can be considered medium to large scale. Although the hotel isn't foreign owned, it is distinctly designed to cater for the needs of the Western tourist and is well integrated into Western travel agencies and infrastructure. Therefore it can still be considered extremely relevant for the purposes of this study. 
A survey questioning the impact a large scale development had on people's lives was central to the research. However, due to difficulties getting survey data from a large scale development in Samoa the research has focused on providing the arguments above from literature and on secondary research aims of seeking the governments views and strategies to deal with tourism and linking these strategies back to literature. 


\section{Chapter 2: Theoretical Framework}

This chapter introduces theoretical frameworks regarding tourism and development and presents the key cases and critiques for alternative tourism and mass tourism. It starts with a highlight of key tourism development theories which have strong parallels with overall development theories with the time for tourism lagging by arguably 20 years (Sharpley \& Telfer 2002). The development theories are particularly important as they provide the guiding paradigms through which development issues are viewed and provide the framework for analysis of the results. Where possible, reference to the Samoan context will be made, as the extreme peripheral nature of Samoa as a remote island nation presents unique attributes and challenges. The theoretical frameworks section is particularly important as it will set the platform for establishing the research environment and how the rest of this thesis is viewed. It will set a position for the researcher in the value laden landscape of research and provides justification and increases validity of the findings (Babbie, 2012).

It is also important to note that the area of tourism, as indeed all of development studies, is highly contentious and there is far from unanimous agreement with the endorsement or rejection of various types of tourism as tools for development. Although few would argue with the goals of poverty alleviation in developing countries, the perspectives on how to achieve this are extremely varied.

\subsection{Tourism and Development}

Development is the raison d'etre of tourism although the developments benefits seem to be alleged as there is little work linking the two fields. The difficulty is compounded as development is an ambiguous and highly contested term. Sharpley and Telfer (2003) refer to development as a process (through which society moves from one condition to another), and also the goal of that process. It is also referred to as a philosophical concept. More broadly it can be seen as synonymous with progress, implying transformational or good change. Early 
theorisations of development viewed development as a unilinear process and were unwaveringly Eurocentric and all but ignored gender inequalities.. The traditional model of development though to the late 60 's relied solely on economic measurements as countries moved though a set of economic steps where GDP increased. It was observed that poverty, unemployment and inequality were unaffected in many countries despite vast increases in per capita income. Increasingly economists called for the dethronement of GDP (Todaro, 2000). From the 1970's onwards, development has tried to take on a less linear, less western and more holistic approach taking on board social and cultural considerations as well as economic. The extent to which tourism contributes to development will depend of a variety of factors. Small island states such as Samoa with limited resources will have a larger emphasis on the industry. This has certainly been the case in the Caribbean, Seychelles, Maldives and other South Pacific islands such as the Cook Islands, Fiji, French Polynesia and New Caledonia. The coastal nature of small islands and its large coast to land ratio is a factor in the natural attractiveness of the destination country plus the size of the country makes it difficult to invest in other industries which are more capital intensive. The UNWTO states that the sector is increasing in importance as the growth in tourism surpasses that of general economic growth. Given the relative size of sector for developing countries and the absolute size of mass tourism and it is difficult to fathom how mass tourism does not play some part in development which is a main thrust of this research.

It is relatively simple to determine the economic contribution of tourism in the form of tourist receipts, percentage of GDP and number of people employed. What is less clear is the contribution of tourism to development and the processes involved in linking tourism to other development outcomes such as poverty alleviation. While there is vast literature on alternative forms of tourism using development frameworks and literature dismissing mass 
tourism as a development tool, there is very little literature which attempts to look at mass tourism in a positive light using development frameworks.

It should be also noted that the concept of development is also highly contested. Todaro's (2000) definition is “the process of improving the quality of all human lives”. Three important aspects are (1) Raising peoples living levels, through relevant economic growth processes, (2) Creating conditions conducive to the growth of peoples self-esteem through the promotion of institutions which promote human dignity and respect, (3) Increasing people's freedom by enlarging their choice variables.

Goulet (1968) takes a slightly different approach with three basic values which represent "The Good Life"

The sustenance of life: All people have the basic requirements, such as shelter, food and health, without which a state of underdevelopment exists. Esteem: all individuals seek esteem, a sense of identity, self-respect or dignity. The nature of esteem varies from one society to the next and may be manifested by increased wealth or material well-being or conversely, in the strengthening of cultural or spiritual values. Freedom: in the context of development, freedom represents increase choice for the individual members of society and freedom from servitude to ignorance, nature, other societies, beliefs and institutions. (Sharpley \& Telfer, 2002).

The notion of self-determination has become an essential component to development where the development process in no longer in the control or trusteeship of advanced western nations (Cowen \& Shenton 1995). Park (2003) laments the prevalence of Eurocentric development in light of the evolution of development theory. What should be noted however is that as development theory has evolved from its focus on GNP and economic indices, its influence has permeated generally into the west and western thinking. This would suggest 
that western views of development have moved on and that Eurocentric approach to development in the 1960's is quite different from a Eurocentric approach today. Even under the old development paradigm all countries have made significant progress in the many areas such as life expectancy particularly in the developing countries of Asia where average expectancy moved from 30's in 1920 through to 50's in 1965 (Rosling, 2009). One must also question whether or not the host countries have the capabilities for self-determination or what shape or form self-determination will take. Is it a form of decision making dominated by local elites or is it more inclusive? Some sort of programme seems logical to devote resource to building local capacity in decision making. Given the absence in many countries for the capacity of self-determination is foreign control necessarily bad? There are many facets of western trusteeship and economically focused development and the area seems worthy of revisitation after 30 years.

In the 1990's the very notion of development came into question. Sachs (1992) argues that the notion of development is fundamentally flawed, is inherently unjust, has never worked and therefore should simply be abandoned. Two key factors have influenced this post development rationale. Firstly, environmental factors saw the 1980's as a 'lost decade of development' where many indices in developing countries went backwards. Secondly, development is seen a Eurocentric philosophy enforcing a belief that 'west is best'. If development itself in doubt then the potential for tourism as a development tool must also be debatable.

The controversy around the definition of development, the value of the definitions, the debate development's Eurocentricity makes this an incredibly difficult subject to be studying. Without an objective frameworks or markers it would be impossible to make any recommendations for change. For the purposes of this essay, Todaro's and Goulet's 
definitions seem worthy basic frameworks which take into account both economic and social considerations.

\subsection{Development Paradigms}

Development theories have broadened from simplistic growth models towards more complex and holistic shifting from a predominant emphasis on economic growth to models which incorporated social, political and environmental considerations.

Sharpley and Telfer (2002) state that development theory can be divided into development ideology (the ends) and development strategy (the means), where the means is the method of implementation guided by a specific ideology. Goldsworthy (1988) argues that development theory remains politically uninformed ... and all development theories, plans and strategies consciously or unconsciously express a preferred notion of what development is and these preferences in turn reflect values'

The below are key theories which dominate development studies and each new paradigm can be seen as a reaction to the one before it although each one of these is still pervasive in today's development literature. What is important in the context of this thesis is that one has an awareness of the inherent bias and looks to the legitimacy each and how they can inform development.

\subsection{Modernisation}

The post-war, post-depression era saw the development of modernisation theory as well as mass tourism with the accessibility of air travel increasing. These together heralded a push on many countries who were seen to have a comparative advantage in tourism (i.e. beaches, surf, sand, temperature, climate) to use tourism as a means to modernisation. 
Modernisation theory is based on a western-centric model of development and assumes a progression of LDC's to a modern western economy passing through various 'development stages'. It espouses state promoted inputs of capital, technology and knowledge are required to as a catalyst to development. Once economic growth started to occur, it is assumed the markets would take over and that the benefits would "trickle down" to the rest of the population (Scheyvens 2002). Emphasis is placed on infrastructure development and communications so contact with the outside world is very beneficial. Mass tourism relies on resources from the North and tourists come from the North to the South thus the dependency relationship is unavoidable.

Britton (1983), Beeton (1998), Scheyvens (2002), and Lea (1988) challenge the focus on economy, and its unidirectional and top down nature, focusing in particular on the power inequalities from the dependency relationship concluding that it is impossible for development to occur as the differential in power leads invariably to exploitation. It is the oldest paradigm and it is generally accepted that broader and more holistic frameworks are required (Sharpley \& Telfer 2002). This theory informs this thesis with the importance of the role of the state facilitating infrastructure and capital and providing a guiding interventionist approach to tourism development. This is contrasted with neoliberalism which advocates a laissez faire approach to tourism and will be discussed later in this chapter.

\subsection{Dependency and Underdevelopment}

Development critics arose predominantly in the 1950's and 1960's as the post war boom faded and holes started appearing in the dominant modernist theory of the time. For tourism there is a lag in the parallel criticisms that occur in the 1970's. One of the major theories is dependency theory where the theorists argue of an unequal power relationship between the West and LDC's initially as a result of colonialism and subsequently vested 
power interests through multinationals leaving LDC's vulnerable and open to exploitation. Britton (1983) uses the example of Fiji and argues that any benefits of tourism have been attained at considerable cost. Although he accepts the benefits of creation of jobs, diversification of the export base, capital and infrastructural development, he argues that the costs far outweigh any benefits. At a national level, resources allocated to the administration and maintenance of tourism and an unequal distribution of benefits amount locals where indigenous groups were largely excluded from control of enterprise and left with unprofitable menial work. Internationally, overseas companies received the majority of receipts through their monopolisation of associated travel support infrastructure such as credit cards, banking, airlines, booking services. Because the control, he argues, lies outside of the country "the allocation of such capital may not result in economic outcomes that are conducive to the national sovereignty or general wellbeing of Fiji's citizens".

Britton (1983) goes further to classify tourism as a vestige of colonialism and asserts that tourism has no long term value to the citizens of Fiji other than a stopgap for what he would consider to be real development. de Kadt (1992) takes a slightly different approach listing the misuse of nature, costs of materialism and loss of culture as the costs of tourism which he considers far outweighs any benefits. Sofield (2003) lists, not exclusively, environmental degradation, cultural commercialisation and bastardisation, prostitution, the introduction of liquor and drugs, the breakdown of family and increasing individualisation. The power inequality leads to dependency which leads to exploitation and a condition of underdevelopment, where fair opportunities are not availed to developing countries nationally nor its citizenry.

Parnwell (1998) questions dependency theory logic because of the way globalisation processes and forces are interpreted and implemented at a local level can have a variable effect on the outcome. Scheyvens (2002) notes that "while larger hotels may be guilty of 
repatriating profits backs to their host countries, they may be preferable to locally owned accommodation some cases as they offer training, job security, better working conditions and higher rates of pay". Harrison (1997) notes that tourism generally provides more jobs and better money and work conditions than agriculture. It should also be noted that globalisation's forces are also in themselves highly heterogeneous and there are a myriad of foreign operators each with a different level of ethics and support for communities. Surpluses in the economy were assumed to move from the periphery to the centre where underdevelopment was happening at the periphery. The accent of Asian nations in particular seems to be empirical evidence some of the concerns of this paradigm as there can be little argument that many development indicators have improved significantly with international trade, particularly in North East Asia. Butler (1992) and Harrison (1997) have criticised dependency for being overly pessimistic.

This theory provides an awareness of the potential of power inequality and embedded tourism which can to lead to monopolisation of benefits and underdevelopment for the host nation. Thus policy where practical and without overriding adverse side effects should be aimed at shifting the balance in favour of the developing nation thereby accruing more of the benefits for the developing nation.

\subsection{Neoliberalism}

The 1980's gave growth to a new form modernism known as neoliberalism in a reaction against policies of high levels of state intervention with prevailing Keynesian theories. The rise of conservative governments at the time added had a great influence on this counter revolution in thinking. While several theories are prevalent in academic circles, neoliberalism dominates policy circles around the world. Neoliberalism promotes market led growth through foreign investment and removal of barriers and an export orientation and also 
assumes that through growth, the benefits will trickle down to the wider community. Not only would the poor benefit from direct employment, improved opportunities and infrastructure, but tourism would also cause a boom in ancillary businesses. Tourism under the neoliberal paradigm remains outwardly oriented and places host locations in a dependent position on foreign operators and guests (Brohman 1996). Neoliberalism has been criticised for its financial strategies, that it is dominated by Western countries and that it neglects social cultural and political relations and issues of sustainability and environment (Sharpley \& Telfer, 2002). Where there is overlap with modernism, neoliberalism does not see a role for the state meaning that tourism should be left to the market and foreign investment and the state's role is merely to sustain an environment free from regulation.

However, it clear that a lassiez faire approach to tourism will not yield optimal outcomes for the host nation. Weaver (2006) and Butler (1992) argue that tourism's poor performance has been due to lack of considered and appropriate planning. Butler in particular focuses on overuse of resource without adequate controls being implemented. Whether or not you buy into the ideology of dependency and it is clear that some level of intervention is required to leave host countries in positions to negotiate favourable terms for their respective countries. In the case of Samoa, land and marketing positioning will be key instruments which government can use to negotiate better outcomes for their citizenry. A straight neoliberalist approach would do away with these interventions and Samoa will do well to be aware of these before succumbing to liberalisation under UNWTO rules and regulations.

\subsection{Jafari’s Adaptancy Platform}

Jafari (2001) uses a system of classification pinning modernist and neoliberalist approaches under the "advocacy" platform and dependency under the "cautionary" platform. Under the cautionary platform Jafari also includes environmentalists who advocate the 
primacy of the environmental issues. Also included are those who are not strict dependency theorists or environmentalists such as Lea (1988), who created counter arguments to any of mass tourism's purported economic benefits. For direct revenues, monopolisation of the industry and high administrative and support costs, for multipliers, high leakages and for employment, low paying menial and degrading work highly subjected to the seasonality and fickle nature of tourists as well as the opportunity costs of developing skills and infrastructure in the tourist industry over another industry. Jafari's (2001) adaptancy platform describes adaptations to the above platforms which are suited to the sociocultural and environmental circumstances of any given community. The most common term for these is adaptations is alternative tourism which will be discussed in more detail later in this chapter. These options are seen and a practical means of averting the issues related with mass tourism and is by definition in contrast with mass tourism. This platform should be noted as being ideologically aligned with the cautionary platform (Weaver 2006). This ideological bias is significant in the context of this thesis as, if there is uncertainty around the claims of those under the cautionary platform, then the emphasis on alternative tourism must also be questioned. Where all the above platforms have the ability to inform issues and perspectives on development they are criticised for being overly simplistic given the complexity and variable nature of issues surrounding tourism and tourism development (Butler, 1992; Jafari, 2001; Weaver, 2006)

\subsection{Jafari’s Knowledge Based Platform}

In light of the complexity of tourism, Jafari (2001) advocates a knowledge based platform. The platform is ideologically neutral (Weaver 2006) and views alternative tourism as part of the solution for development in addition to mass tourism. Jafari (2001) states that any form of tourism comes with associated costs and benefits. Jafari (2001) criticises the 
adaptancy platform for its ideological bias, its concentration on local issues where issues at a global level also need addressing and the fact that mass tourism is so established in many areas that is would be hard to reverse. Jafari contends mass tourism needs addressing with strategies for planning and management and is not inherently inferior to alternative tourism but rather presents its own set of issues and problems some of which are also associated with alternative tourism. What is advocated is a 'scientification' of the field of tourism where tourism is studied without ideological bias, and decisions on mode and scale are based on scientific analysis of the characteristics of the destination and planning and management strategies which have worked empirically on other similar destinations .

According to Dann et al 1988: "Whether this ideology is located politically to the left (e.g. tourism is exploitative in the framework of dependency) or to the right (e.g. tourism provide the basis for universal brotherhood), it still does not explain the phenomena". (Dann

et al., 1988 cited in Sharpley \& Telfer, 2002). Dann makes his case that more empirical study is required and that the development paradigms are analysed for the extent to which they have or have the potential to inform tourism research.

Butler (1992) also laments the lack of uniform and scientific measures in the field of tourism noting it is difficult to make fair comparisons and therefore conclusions regarding tourism without this uniformity. This knowledge platform is the key platform for the remainder of this thesis. A uniform and longitudinal framework for measuring development in a host destination will be suggested in the results section.

\subsection{Leakages and the Multiplier Effect}

This is one of the major criticisms of the mass tourism. The receipt of tourism earnings overseas is known as "leakage" and has two forms, import and export. Import leakage occurs when visitors demand goods that the host country cannot supply, either 
because of an absence of local suppliers or the local standards are not high enough. Export leakage arises when foreign companies take profits back to their host country. A 1996 UN study, carried out in the Caribbean evaluated the contribution of tourism to national income, gross levels of incomes and/or gross foreign exchange. From the data presented, St. Lucia had a foreign exchange leakage rate of $56 \%$ from its gross tourism receipts, Aruba $41 \%$, Antigua and Barbuda 25\% and Jamaica 40\% (www.oceanatlas.org). This diversity among results demonstrates that there are variable factors which can affect a countries ability to hold receipts within the host country. Lea (1988) suggests it is higher concluding leakage rates of 70\%. Berger (2004) points out that either trickle down or leakages are emphasised depending on one's particular perspective on tourism development and is "used interchangeably as a currency in the discussion of tourism".

The tourism multiplier effect is the circulation of tourist dollars in the host economy feeding though and encouraging growth in the primary and secondary areas of industry. This can be seen as tourist dollars retained in the host population and the opposite of leakages discussed above. The multiplier become smaller when there are high levels of leakages or there is a high dependence on imported goods. Mihalic (2002) argues that even low value income multipliers do not necessarily suggest that the economic benefits of tourism to the destination are minimal. Butler (1992) argues that the absolute dollar terms retained in a destination is a more meaningful measure than the percentages.

It is generally accepted that greater multipliers are pro-development in the host population and leakages seen as a debit. Therefore it seems natural to assume that strategies which enhance the multiplier effect (without affecting other considerations) are prodevelopment. The proviso here is that other considerations are not affected which is difficult in practice. For example, the multiplier would be enhanced if a government were to stipulate 
the consumption of local fruit. However, this may affect the commercial attractiveness of the host destination and the competitiveness and marketability of the tourism venture.

The key outtakes here are that strategies should be employed to reduce leakages where appropriate and there is conflict over use of absolute or percentage leakages as indicators for tourism's capacity for poverty alleviation. The percentages also represent issues of fairness and control so high leakages fit easily into the dependency paradigm. The alternative tourism debate in a leakage context can be framed, it is better to get a smaller slice of a very big pie than a large portion of a small one?

\subsection{Alternative Tourism}

Under the adaptancy paradigm, smaller scale 'alternative projects' have found favour with academics (Lea 1988, Beeton 1998, Scheyvens 2002, , Park 2003,Sofield 2003) because they place control within the community and decentralise the decision making process. Timothy (2002) states that from large scale (foreign owned projects in particular) 'relatively few of the positive impacts accrue to the host economies'. He argues the same for large scale locally owned projects, which invariably are controlled by local elites. Whilst critical of the modernist/neoliberalist paradigm and the adaptancy, authors see dependency as overly simplistic and have promoted alternative types of tourism. Scheyvens (2002) notes that "studies of the global-local nexus demonstrates that the power is not unidirectional. Alternative tourism has emerged from the perceived failure of modernism to provide for the whole of society and the lack of viable practical alternatives from the dependency camps." The alternative or adaptancy development paradigm is seen as a pragmatic, broadly based approach which arose out of criticisms of the advocacy and dependency models (Sharpley \& Telfer, 2002). Alternative tourism is noted for its alternative to mass tourism and is characterised by small scale, community level decision making, low leakages, and interface 
with the local citizenry thereby facilitating possibilities for economic transactions. The assumption is that the alternative forms of tourism have less negative effects without diminishing the positive economic effects (Butler, 1992).

Berger (2004) claims that "these alternatives have led to a more nuanced and wide ranging picture of tourism development." Adams et al. (2005) promote alternative tourism as a rare panacea which is implemented properly can produce "improved livelihoods and living standards without the attendant damage normally associated with mass tourism" with the ability to "work simultaneously on agricultural practices and food security, create other income generating activities, conserve and protect biodiversity hotspots, improve community awareness of health and environmental issues, promote land tenure security and build civil society". In contrast, conventional tourism "consumes resources to the point of environmental collapse, destroys local and indigenous culture .... and lacks sensitivity towards local and environmental needs"

Scheyvens (2002) lists justice tourism, budget tourism, ecotourism and gender sensitive tourism as novel ideas and approaches. Ecotourism has become one of the fastest growing sectors of the tourism industry growing annual 10-15\% worldwide (Miller, 2007). These alternative types of tourism are by nature small scale with an appreciation for the social and ecological environment. They place an emphasis on sustainability and are said to solicit community involvement in the planning and implementation. Increase participation is linked with concepts of empowerment and local control over decision making (Sofield 2003). Indigenous development theories are promoted as is the role of women in the local environment. Along with the focus on people, alternative development is closely associated with environmental and sustainability concerns. Hitchcock, King and Parnwell (1993) conclude that tourism "must take into account the social and ecological carrying capacity of an area...locals needs must not be superseded by those of outsiders and local knowledge" 
Moreover, they state the "main weakness of current top down strategies is that they fail to solicit the views of locals... who inevitably have to accommodate all the impacts arising from tourism development."

One of the key benefits of the alternative approach is said to be the multiplier factor that is the circulation of tourism dollars spent and retained in the host country. However, Harrison (1997) has stated that this is very difficult to measure in practice and as discussed earlier in this chapter there is controversy over the whether a larger portion of smaller 'pie' is more meaningful than smaller portion of a larger 'pie' and whether absolute dollars retained is more meaningful than percentages.

Butler (1992), Weaver (2006), Harrison (1997), Jafari (2001), de Kadt (1992) and Pearce 1992 challenge the superiority of alternative tourism in development over its conventional counterpart. While they accept it has a role to play in development and communities can and should choose alternative tourism in some instances, claims that alterative tourism is inherently superior is misguided as alternative tourism comes (as does conventional tourism) with its own set of costs and benefits (Butler 1992, Weaver 2006). Their stance is alternative tourism should be part of the development mix with conventional tourism as opposed to a superior replacement for it. They claim that the preference is borne from an ideological bias (Butler 1992) or moral indignation (de Kadt 1992). Weaver (2006) suggests that there may be a disconnect between what adaptancy advocates want to impose on host populations where local populations may actually prefer to mass tourism.

Butler's (1992) major issue the sheer economic value of mass tourism. Mass tourism is an incredibly successful product occupying a lion's share of the tourist market. The direct spending by tourists is relatively easy to estimate and Bryden's (1973) analysis of the commonwealth Caribbean estimates government revenues from taxation at between $10 \%$ and $15 \%$. People enjoy not having to make their own bookings, being able to buy goods and 
services without learning a foreign language, and being able to stay in relative comfort. This can be taken one step further to include having the confidence and reliability of multinational brands which convey the security of quality standards, guarantees, customer service. This particularly important in LDC's where mass tourists will have more than average reservations about safety and reliability of the product. They need a home base away from home to retreat from the exotic and relax in relative comfort. Mass tourists see the above as benefits and alternative tourism whilst growing has a much narrower consumer base and appeal. By rejecting conventional tourism, a lion's share of the tourist market (and potential taxation) is also being precluded. Alternative projects just by nature of their size are limited to the extent they can accrue economic benefits to the community. That is not to say the development benefits will necessarily be larger, but the potential to have a more positive impact certainly is. Scale obviously needs to be balanced by social and environmental considerations but size does matter.

Berger (2004) notes two common criticisms of alternative tourism. Firstly the argument that preservation concerns are prioritised over concerns for local people leading perhaps to the 'zooification of host cultures for the pleasure of first world guests.' His second concern is that projects have tended to view the community homogeneously and this has led to a tendency to empower local elites rather than the community as a whole. Weaver (2006) lists an example of the marginalisation of unmixed African decent in the Caribbean and Ranck (1987) shows a case where alternative tourism development has perpetuated existing clan rivalries.

Smith and Eadington (1992) question the community participation and decision making. Who is participating? Who are the decision makers? Are they representative of the community? Do they have the capacity of understand the implications of their decisions? Are local elites being empowered. Butler (1992), de Kadt (1992) and Jafari (2001) claim 
adaptancy advocates have a simplistic, idealisation of the outcomes from the platform and critique the assumptions behind how it is presented. According to Butler (1992, p35) "Mass tourism need not be uncontrolled, unplanned, short term or unstable and green tourism is not always inevitably considerate, optimising, controlled, planned”. Butler (1992) notes two conditions where alternative tourism may in fact be more harmful that it's conventional counterpart. One is a fragile eco-attraction, which is more appealing to alternative tourists but holds little appeal to mass tourists and the other more common claim that over time, alternative types of tourism have the potential to be more damaging as interaction with the local population in encouraged. Scheyvens (2002) states new forms of tourism have the potential to be more destructive than conventional forms, especially as they encourage interaction. She also notes that a prevalence of these alternative tourism projects is also not necessarily desirable. Scheyvens and Purdie (1999) state that while the rhetoric states there is much support for community based alternative tourism ventures, it is difficult to find successful examples of this in practice. They cite recent studies where local elites dominate the product and benefits.

Taylor (1999) notes that there is much acceptance of the idea of community participation but little understanding of the complex mechanics to make this successful in practice. He states that "much depends on the individual cohesiveness of a community or to the extent competitiveness and individualism are evident." Scheyvens and Purdie (1999) also note that these small scale enterprises need the community to have a plethora of skills such as marketing, finances, resource management, and human resource management to run their operations. Milne (2005) has identified some serious gaps in the tourism capabilities of South Pacific small and medium enterprises (SMEs) implying a lack of ability to take advantage of alternative types of tourism. Van Der Hoeven (1980) criticises the basic needs approach 
saying it may impede long term economic growth, underestimates the importance of political change and can lead to too much state control.

Thomlinson and Getz (1996) state that confusion has arisen over definitions of alternative tourism and its products because the term ecotourism in particular has been used primarily as a marketing tool so tourists who think they are getting an allegedly more sustainable and ethical product may in fact not be anyway. Weaver (2006) and Pearce (1992) claim that attempts by the adaptancy platforms to disassociate themselves from mass tourism are disingenuous as alternative tourism relies on mass tourism structure at different stages in the tourism system. Airlines are the most visible example of this as most alternative tourists would use large airlines to get to their destinations. In many instances, mass tourism would actually support alternative tourism as without mass tourism, there would not be the flight frequency and capacity to many destinations and the cost of travel would be out of reach to many alternative tourists. The critics (such as Butler, 1992; de Kadt,1992; Jafari, 2001; Weaver2006 and Harrison1997) also include problems with building consensus, barriers to participation, lack of accountability, weak institutions and lack in integration with international funding sources.

From an efficiency perspective alternative tourism might also be questioned as projects would mean that across a country a lot of resources are being duplicated the same economies cannot be gained as for larger scale project. For example, for marketing, Aggie Grey's hotel would need to communicate with potential tourists to make their name recognised and make it synonymous with high end accommodation in Samoa. In contrast, each local alternative accommodation type, each with a slightly different variant of product as a result of local input and implementation needs to communicate with potential tourists. Weaver (2006) suggests that over time the more successful operations may become larger and the alternative nature and benefits of the alternative will be lost. 
Overall, there is far from consensus over the role and value of alternative and conventional tourism and the debate and the divergence in paths seems to stem from major differences in theoretical perspectives on tourism and development. Adams et al.'s (2005) analysis that mass tourism leads to social and cultural degradation is countered by Butler's (1992) claim that alternative forms of tourism lead to greater degradation because of the encouraged participatory nature of alternative tourism. Equally, Butler's (1992) claim regarding the sheer size of the mass tourism market seems to make assumptions regarding the ability for benefits to trickle down.

What is required is a scientification of the discussion (Dann 1988 cited in Sharpley \& Telfer, 2002, Pearce 1992, Butler 1992, Jafari 2001 and Weaver 2006). Where there have been surveys and impact studies which show the value of alternative tourism (Scheyvens 2002, Park 2003 and Adams et al., 2005)), other studies also show alternative tourism to be problematic (Ranck 1987, Scheyvens \& Purdie 1999 and Weaver 2005). While the studies do not demonstrate whether or not conventional tourism has value as a tool for development, the fact that alternative tourism is shown to be somewhat problematic in practice adds weight to the argument for reopening the case on conventional tourism.

Surprisingly there is relatively little material which surveys locals and which is directly aimed at mass tourism. For example Britton (1983) uses the case of Fiji, and Lea (1988) uses the Caribbean as examples to discount mass tourism as a development tool. However, their analysis is aimed primary at showing leakages from the economy or having external subjective judgments regarding social change or the quality employment. Lea's (1988) example dates back to 1969 and Britton (1983) from the late 1970's. Not only is this initial data quite dated, it lacks the bottom up feedback that surveys aimed at locals can provide. For example one study in Indonesia showed that locals found working even in 
menial jobs at a large multinational hotel chain extremely rewarding and it was seen as somewhat of a status symbol (Cukier, 2002). This is in contrast to the exploitative nature of employment that cautionary and adaptancy platformists would espouse.

Butler (1992) asks whether the real problems with mass tourism are endemic and unavoidable or a function of the dimensions and numbers concluding both. "The nature of tourism to some degree determines the nature and pattern of growth and unless checked and controlled will inevitably create a set of problems." (Butler, 1992, p. 34).

Given the uncertainty and questions raised regarding the benefits of alternative tourism, some of the unique costs, empirical evidence showing problems around distribution of benefits in practice, issues with the age and methodology of analysis from the late 1960's and 1970's and the fact that it only appeals to a small segment of the tourism market, I believe there is enough uncertainty to re-examine the case on conventional tourism using scientific and preferably longitudinal methods and surveys which garner feedback from local communities. Weaver (2006) maintains that the focus for research needs to be on making conventional tourism more sustainable as this is the format that makes up most of the tourism market and both conventional and alternative forms of tourism entail costs and benefits. The aims of sustainability, cultural, social and environmental awareness and mitigation of negative impacts espoused and emphasised by alternative tourism need to be translated for conventional tourism. This research feeds opportunely into the above using a survey method to evaluate the value of conventional tourism at a tourist resort in Samoa.

\subsection{Theoretical Perspectives Conclusion}

A large portion of this thesis has been directed at examining the theoretical perspectives as the choices taken at here at this point in the dissertation will guide the remainder of the thesis profoundly both consciously and unconsciously. Those who have adopted the adaptancy platform have made clear arguments and counter arguments against 
those who have adopted the knowledge platform and vice versa. What is clear is that research directly aimed at mass tourism using social and environmental frameworks (as opposed to just economic) is clearly lacking. What is also unclear is how these benefits are distributed especially at multiplier benefit levels.

While I have chosen to adopt the Jafari's knowledge platform, a decision which is driven in part from the arguments made by Butler (1992), de Kadt (1992), Pearce (1992), Jafari (2001), Weaver (2006), Harrison (1997), and driven in part from my personal political preferences, it is by no means resolved that conventional tourism does play a role in development as survey style empirical evidence is lacking and further research is required. The other platforms and theories are still valid insofar as they inform the development process. For example, dependency theory and its ability to inform about issues of peripherality in Chapter 3. 


\section{Chapter 3: Key Literature and issues}

The purpose of this next chapter is to explore key literature issues and concepts surrounding tourism and tourism development and link them to how they may inform the direction of the research in this thesis.

\subsection{Butler's Destination Life cycle}

Butler (1990) proposes a widely-accepted model of the lifecycle of a tourist destination. A destination begins as a relatively unknown and visitors initially come in small numbers restricted by lack of access, facilities, and local knowledge, which is an apt description for most parts of Samoa outside of Apia.

As more people discover the destination, its attractions and the amenities are increased and improved tourist arrivals then begin to grow rapidly (Exploration) and exponentially toward some theoretical carrying capacity (Stagnation) which involves social and environmental limits. The rise from Exploration to Stagnation often happens very rapidly. There are possible trajectories beyond Stagnation. Examples of things that could cause a destination to follow upward trends are technological developments or infrastructure improvements leading to increased carrying capacity. Examples of things that could cause a destination to follow downward trajectories are increased congestion and unsustainable development, causing the resources that originally drew visitors to the destination to become corrupted, or no longer exist. A sudden decline in tourist numbers can happen following a disaster or crisis, such as the Samoan tsunami of 2009.

The key outtakes for this cycle for Samoan planners is the rapid path of the expansion during the Exploration phase which needs to be taken into account in planning and the need for intervention at Stagnation to prevent decline.

\subsection{Sustainable Development}


Sustainable development is a pattern of resource use that aims to meet human needs while preserving the environment so that these needs can be met not only in the present, but also for generations to come. The term was used by the Brundtland Commission which coined what has become the most often-quoted definition of sustainable development as development that "meets the needs of the present without compromising the ability of future generations to meet their own needs". It takes away from the economic focus of earlier development paradigms and instead focuses on preservation and the environment. Critical to this approach is the ability of initiatives to provide long term benefits. This approach has been criticized for its Eurocentricity (it is still a western concept), its vagueness, its failure to recognize sustainability as a luxury in the context of developing countries desperation for economic growth, and its inability to predict the needs of the future "what is to be sustained and who decides and defines this?" (Redcliff 2002)

\subsection{Practical Strategies for Sustainable Development in Mass Tourism}

From the review in the alternative tourism section it is concluded albeit controversially that it can be counterproductive to limit yourself to one dominant development paradigm for tourism as each has its merits and drawbacks and it is the process for development rather than the tourism product per se which can determine the outcome of a project or indeed the project selection. Therefore the next section is dedicated to finding practical literature, processes and cases available around process elements attempt to positively correlate mass tourism with development.

As there does not seem to be single prescription for tourism development some authors have sponsored the idea of trial and error. On the surface this seems a logical approach where an industry implements a project and adjusts accordingly. However, in 
practice this method may be impractical given uncertainly around business proposals; it can be difficult to finance a proposal with this kind of uncertainty and especially with larger scale projects much capital has been invested and would be difficult to reverse. Overall this approach seems disorganised and ad-hoc although perhaps there are elements of this approach which could be implemented successfully. There is very little evidence of where this approach has been deliberately applied in practice, but it does have some appeal in that host destinations often do not fully appreciate what they are getting in to until it is perhaps too late. Also issues with implementation and unforeseen conflicts and problems can be ironed out. Although with some theoretical merit, in practice it is difficult to implement. Who chooses the timeframe for implementation and evaluation? Who chooses what projects gets the green light initially?

A limitation the number tourists has also been proposed and this has varied from very small numbers so as to have negligible impact on the host environment through to the carrying capacity of an environment. Tourism Carrying Capacity is defined by the World Tourism Organization as "The maximum number of people that may visit a tourist destination at the same time, without causing destruction of the physical, economic, sociocultural environment and an unacceptable decrease in the quality of visitors' satisfaction.”(Kandari \& Chandra, 2004, p. 106). In practice these measures can be very subjective and what is considered 'acceptable' will vary greatly across a population. It should also be noted that each limitation of a given tourist also represents the limitation of a potential revenue stream so the two factors need to be balanced.

In Mauritius there is a strategy in which host and tourist populations are segregated to negate presumed negative effects on culture. Whether or not tourist populations have a negative effect is wildly debated and depends a lot on one's perspective. Harrison (1997) notes that cultures are not static but evolving things and it is erroneous to assume that host 
cultures are necessarily 'better'. There are elements such as drugs and prostitution which are generally seen as negative but these can arguably be dealt with law enforcement initiatives. Page (1999) states that surveys in Mauritius suggest government fears concerning cultural damage are not shared by the population. Altman and Finlayson (1992) describe aboriginal tribes who have opted to not participate in tourism directly and instead benefit indirectly from arts and crafts and a share of proceeds from visits to heritage sites. Butler (1992) laments that where mass tourism is segregated, it is criticised for not interacting with the population and thereby limiting the potential for transactional activity but where it is unsegregated it is criticised for its cultural degradation.

The Mauritius government and Samoa have taken a cautious approach to tourism by limiting the rate of growth. In some government documents pre-2000 Samoa specified 5\% as being a target growth rate for tourism whereas the latest development plan has targets of 5\% to $10 \%$. The upside of this would be giving the local population time to increase their capacity to adjust to any changes. In addition to this strategy, the trial and error approach can be implemented as change would be controlled and any unforeseen negative aspects of tourism can be dealt with on an ad-hoc basis. The downside would of course be the opportunity cost and decisions around which projects get priority.

Page (1999) also states the Mauritius government has had a role in shaping the culture of the place by promoting itself as a high end luxury destination. This is particularly relevant as destinations need to compete against one another for foreign capital and may be persuaded as a result of the competition to agree to conditions of taxation or regulations which may be counter to the national interest. A unique position in marketing limits the alternative destinations available to a foreign investor and puts the host country in a stronger negotiating position so fair regulatory and taxation levels can be maintained. 
The 2007 UNCTAD report on LDC's has identified that in Asian LDC's, garment related FDI inflows have not increased the technological capabilities and suggest training levies on firms to stimulate upgrading. The same could apply to tourism and will be discussed further in the section on employment and tourism.

There are several practical strategies which can be adopted to increase outcomes for destinations and not all will be valid or desirable in all cases or situations. Marketing and employment seem to be areas which are relatively unexplored at this stage and seem worthy of further exploration as it is believed that these hold particular relevance and potential for Samoa and may have universal applicability for tourism development in the periphery, both of conventional and alternative formats.

\subsection{Ethics in Conventional Tourism}

Within the global-local nexus it should be noted that the global tourism is not static and is changing and evolving as well. Awareness of social and environmental issues are increasing with many investors and consumers demanding ethical accreditation though tourism groups such as Green Globe and EC3 (Sharpley and Telfer, 2002). Awareness and use of triple bottom line accounting is gaining in popularity with many business schools teaching this and adding ethics to their curriculum (Blackman, 2011). Triple bottom line (TBL) basics expands the traditional reporting framework to include social and environmental considerations in response to increasing awareness from consumers regarding ethical and social issues (The Economist 2009).

People, planet and profit describe the three pillars of triple bottom line and the goal of sustainability. People pertain to fair and beneficial business practices toward labour and the community and region in which a corporation conducts its business. A triple bottom line (TBL) enterprise seeks to benefit many constituencies. In concrete terms, a business would 
not use child labour and monitor all contracted companies for child labour exploitation, would pay fair salaries to its workers, would maintain a safe work environment and tolerable working hours, and would not otherwise exploit a community or its labor force. A TBL business also typically seeks to give back to the community through sponsorship of community programs. Planet refers to sustainable environmental practices. A TBL company endeavors to benefit the natural order as much as possible or at the least do no harm and curtail environmental impact. A TBL corporation tracks and manages its consumption of energy and non-renewables. Lastly profit is self-explanatory but should be noted that a corporation which isn't financially sound is not sustainable over the long term regardless of its social and environmental credentials. Profit may include economic impacts to the host society (International Institute for Sustainable Development, 2011).

Issues with quantifying this bottom line are that it is relatively new, problematic and often subjective. Issues with TBL also include the inability to add these pillars up to arrive at a grand total. How do you meaningfully equate cash with social and environmental considerations? (The Economist, 2009). Care must also be taken to ensure a degree of reality behind the public relations and the extent that each is prevalent is up for debate. The UNWTO 2004 document of Small Island Developing States determines that governments and organisations must take a step beyond rhetoric and put objective measures, thresholds and goals in place for society and environment (UNWTO, 2004).

Despite growing awareness of issues the prevalence of ethics in conventional tourism is debatable. Weaver (2006) suggests ethical notions of right and wrong are open to interpretation and can differ especially across countries and the financial situation of a company will dictate it's appetite for ethical, social and environmental concerns.

Weaver (2006) notes the emergence of green consumerism which is growing rapidly albeit off a relative small base. The Economist (2009) notes fair trade is currently focused on 
cotton, coffee, bananas, chocolate and tea but despite the hype it still only occupies a relatively small share of total supermarket sales. A quick scan of the consumer websites for Hilton, Hyatt, Marriott and the Sheraton shows little concern for social and environmental issues. This is despite a survey showing $70 \%$ of US air travelers being more likely to choose a hotel with strong environmental credentials (Webster 2000). These surveys have to be however viewed with a degree of skepticism, as consumers will say they want more ethical and socially responsible alternatives but are often not willing to sacrifice price, comfort or quality. Where there is an intersect between cost savings and environmental concerns, the hotels seem to have embraced these initiatives. For example a recycling program by Sheraton Hotels saved $\$ 7000$ per month as well as dumping fees (Webster 2000) and the now ubiquitously used environmental appeal to consumers to use their towel and sheets again which obviously results in savings to the hotel. While the trend for green consumerism represents a possible paradigm shift and has penetrated other mainstream categories it would be fair to say it has not yet penetrated conventional tourism in a significant way. Therefore conventional tourism needs to be evaluated scientifically given the status quo.

The most compelling argument for ethical behavior in tourism is self-interest. Purdie and Sheyvens (1999) show a case in the Pacific where a large hotel chain was forced to close because of a lack of respect for the local environment. Weaver (2006) points to the in situ nature of tourism where the production and consumption is in the same place. Therefore it is in a corporation's best interests to maintain the environment for the tourists and keep a degree of social harmony for fear of fewer tourists as a result of environmental degradation or social discord. Butler (1992) maintains that this alone isn't enough and cites Hardin's tragedy of commons where a lack of clear assigned responsibility and ownership of land or resources will lead to that land or resource being used beyond its capacity.

The implications for Samoa are that it needs to vet potential investors and evaluate 
them for their record on social and environmental concerns in other destinations. Preferably they will use Triple Bottom Line or a variation thereof and be in a sturdy financial situation. More controversially, land ownership and responsibility needs to be clarified so as to avoid the tragedy of commons Butler (1992). Land and land tenure is a particularly topical issue especially in the pacific and will be discussed in more detail later in this thesis

\subsection{Tourism and Employment}

Liu and Wall (2003) have stated that many tourism plans give inadequate attention to human resource capability and development of the destination country thus impeding the benefits and participation of locals. The premise is that though greater knowledge of tourism and associated skills locals will be in a better position to participate and take advantage of tourism potential. Although most tourism plans incorporate a human resource perspective, content is focused on hospitability services as opposed to taking broader approach. The quality of the jobs and the qualification requirements of the tourism workforce get little prominence. Liu and Wall (2003) compare the tourism plans of Oman in 1991 and Mexico in 1989 to1994. Oman's emphasis has been around the training of tourism skills including English and employment considerations cover supply and demand with the main consideration being given to hotels. In comparison Mexico’s tourism plan has government initiatives put in place to “develop students' vocational, professional, and research skills to create the scientific and technological knowledge necessary to increase the level of efficiency and productivity of the industry and to place the country on the cutting edge of international competition in this field" (Casado 1997, in Liu \& Wall, 2003). In many tourism plans, although there is recognition among planners and academics as the value of community participation useful techniques and mechanisms are seldom identified. According to Liu and Wall (2003), the regular practice is to hire a few modestly paid local 'experts' to 
accompany a highly paid team of consultants and even then the focus has been on fulfilling industry's staffing requirements as opposed to taking a broader development perspective. Also the focus has been on the needs of large scale multinational corporations as opposed to catering for needs of medium and small locally owned enterprise. The skills need to cover not only the operational skills of enterprise but also aspects of ownership and access to capital. Currently, many developing countries do not have the technical expertise, nor the education and training programs in place to cultivate the citizenry who wish to become involved in tourism (Milne, 1990). This has left senior and managerial positions to be left to be taken up by expatriates leaving lower less skilled positions to the locals. The has been a frequent critique of large scale tourism but as shown in Cukier (2002), tourism may be seen as seen a menial and degrading work in developed countries and academics have extrapolated this thinking to the developing world. However, her empirical work in South East Asia has shown that employees are extremely proud to be working for the large organisation and it gives them status and prestige among their communities. Furthermore, when compared to previous or alternative occupations in agriculture of manufacturing, conditions were far more favourable (Harrison 1997).

Nuruyani (1998) cited in Sharpley and Telfer (2002) repeats this sentiment differently by stating that a region can absorb tourism in a more positive way if it has the internal capacity to integrate and create the linkages, adapt its organisation structure and to handle the long term, more integrated development.

Greer (1995) states that

In a growing number of organizations human resources are now viewed as a source of competitive advantage. There is greater recognition that distinctive competencies are obtained through highly developed employee skills, distinctive organizational cultures, management processes, and systems. This is in contrast to the traditional 
emphasis on transferable resources such as equipment. . . Increasingly, it is being recognized that competitive advantage can be obtained with a high quality work force that enables organizations to compete on the basis of market responsiveness, product and service quality, differentiated products. (Greer, 1995).

This paradigm shift in human resource management represents and shift from the previous paradigm of poor industrial relations and struggles between workers and management to one where management seek the engagement and training of employees even unskilled. There will be huge variation country to country and invariably the shift is more pronounced in developed markets than developing. However, this shift has has great potential both in terms of negating the claims regarding the exploitative nature and in private enterprise taking a more direct role in building employment capacity in host destinations.

In order for Samoa to benefit the most from tourism is critical for Samoa to form private public groups to form an integrated human resource development plan. Without such a coordinated effort and maintained focus, Samoa will not use attain optimal value from conventional tourism.

\subsection{Scale and Control of Tourism Development}

The concepts of scale and control are vital to this thesis and to the legitimacy of the alternative development paradigm as applied to tourism as it is assumed that larger scale, foreign owned establishments result in high leakages and locally owned establishments result in low leakages. Britton (1983) examined the enclave model of tourism where tourists arrive in the destination areas and are transported to hotels and resort enclaves. The arguments here are that the sites are designed around the requirements of tourists, are dominated by multinationals that control and adapt the physical and cultural environment to meet the needs 
of tourists. Freitag (1994) cited in Sharpley and Telfer (2002) argues that the enclave resort model used in the Dominican Republic exploits the lower classes as cheap labour while national elites and foreign nationals earn higher incomes. Scheyvens and Purdie (1999) maintain that control is a critical element, citing issues with tourism enterprises in Vanuatu which were controlled by outside interests and pointing to a successful case where an operation asserting that the success was due to the control as authenticity was maintained and cultural norms were valued as opposed to something which should be overcome.

The hotel researched in Samoa in this study are of the enclave resort type where the most of the needs of the tourists are found within the resort and the design of the operation is clearly for tourists as opposed to adaptations to cater for the staff or the surrounds. Should this model be shown to accrue significant benefits to the host populations, it will call into question the need for local control.

\subsection{Government and Tourism}

The level of government involvement is closely linked to the four development paradigms and the perception and role of government is also intrinsically related. Brohman (1996) cited in Sharpley and Telfer (2002) argues that "market forces on their own are not capable of resolving issues related to long term sustainability and distribution of the costs and benefits related to tourism". The Economist (2008), agrees, lamenting the Costa del Sol had become the Costa de Concrete. It advocates a balanced approach similar to that of a company with a capital investment. The capital needs to be looked after to deliver long term sustainable benefits rather than delivering shareholders with initial big return at the opportunity cost of future returns. Telfer and Sharpley (2002) argue that tourism planning is essential to integrate tourism with the broader social and economic needs of the national as well as integrating the infrastructure needs of tourism with that of the rest of the economy. 
They also state that the political ideology of the government can determine whether a government favours large resorts or hostels, ecotourism or casinos. Ioannides (1989) cited in Sharpley and Telfer (2002) identifies two broad roles for government to play. First, establishing a forum for suppliers to co-ordinate activities and second as that of promoter. Hall (1994) outlines seven roles of government; coordination, planning, legislation/regulation, entrepreneurship, stimulation, social tourism and interest protection. He also notes that the government may act in contrast with the preferences and will of the people in the host country.

\subsection{Peripherality and Island Tourism Development}

Concepts and issues of peripherality are closely linked with dependency theory discussed in the previous chapter and refer to the relationship between the North and South. In addition the political economy function it also has a geographic function and both need to be explored with respect to development in small islands and the pacific.

Samoa has a colonial history with Germany and Britain and that history and existing ties are said to exert an exploitative influence (Britton 1982). Sofield (20033) observes three spatial systems which continue this influence, namely the colonial government, the traditional systems of governance and the missionary system. With the engrained systems of governance and influence, local elites are able to monopolise the benefits from tourism (Overton 1999). For the benefits to be distributed effectively, these factors must be overcome.

Sharpley and Telfer (2002) state that tourism is the development option of choice for many islands where there is a lack of resources and a limited range of other economic activity. Butler (1996) and Pearce (1992) suggest that there is a common set of issues faced by island nations namely; 
- Vulnerable to external influences

- Have limited local markets

- Lack a critical mass

- Have poor communications

- Poor transport links with potential markets

- Limited infrastructure

- Limited bargaining power

Generally speaking Butler argues, the smaller the island, the less control the host population has. The above contribute to the peripheral/small island nations being dependent on their immediate core. In order to develop tourism, investment in infrastructure and improvement of access is required.

On a global scale the island nation is more dependent North-South relationships and is subject to exploitation especially when alternatives are limited. On the other hand the North can also provide access to peripheral areas by aiding investment in infrastructure and subsidising transport. On a local scale governments can improve access to their peripheral areas by making conscious investments in rural or periphery areas (Overton 1980).

On a global, regional and local levels issues of peripherality must be addressed to avoid exploitation and marginalisation. Intervention is required in terms of communications, access, and infrastructure to aid development of the periphery to help them to develop linkages to the core and take advantage of tourism. 


\section{Chapter 4: Methodology and Research Design}

This next chapter describes the methodology and practical methods used during the research. The research involved the following processes:

- A review of literature pertaining to tourism development and tourism in Samoa

- A review of literature pertaining to the culture and history of Samoa

- Analysis of tourism related documents emanating from various government departments, especially the Samoa Tourism Authority and the Samoa Ministry of Finance (which includes investment promotion)

- A research trip to Samoa staying at the largest scale resort in operation at the time (Aggie Grey's Resort and Spa) including field observations and informal chance conversations with local staff

- Key person interviews with pertinent government officials in Apia and Samoan government representatives in Auckland

- It was hoped to have formal and in-depth interviews with locals and management working at the aforementioned medium scale resort in Samoa

After long periods of postulating by the management of the hotel, the hotels were not supportive of the process. It would have been possible to approach employees and surrounding villages directly. However, this was deemed to be too dangerous as it may have risked the livelihoods of employees at the resorts which is far too great a cost for this research. Therefore the survey component was abandoned.

This is extremely disappointing given the key to this research should have been an investigation into the changes in positive and negative livelihood for employees of large scale tourism as well hearing first hand from the locals and whether their views supported or 
contradicted that of adaptancy academics who paint pictures of large scale tourism exploitation and subservience of host populations.

The research was designed around Goulet's (1968) and Todaro's (2000) definitions of development and sought to attain information from interviewees, both negative and positive with respect to:

- Basic Standard of Living requirements - food, shelter, water, clothing

- Sense of identity, self-esteem and pride

- Freedom and opportunities such as education and training

- The above for women

Even with management approval the research was always going to be subject to some bias as employees would fear repercussions from their employers regarding negative commentary.

I designed a questionnaire for 30 employees. Employees were chosen for this initial research because of the direct nature of their employment and they have the strongest links with the ventures. Future research should also aim to cover indirect employees (employees from adjacent restaurants, airports, cafes and supporting ventures frequented by tourists) and subsequently from tourism multiplier beneficiaries although this is more difficult.

The questionnaire was semi structured so as to elicit open and unprompted feedback. It covered the following key aspects of development

- $\quad$ Basic requirements - Food, shelter, water, health, spend

- Sense of identity, self esteem and pride

- Freedom and opportunities such as education and training

- The above with respect to women 
With the survey part of the thesis in jeopardy, focus and research aims were changed to interviewing government officials for their feedback and strategies on tourism in order to investigate how they fit in with current tourism literature, analysing the latest tourism development plan and making informal observations from Aggie Greys Lagoon and Resort and Hotel. What are the Samoan government's key options; what are the key issues regarding larger scale development and what strategies do they have in place to deal with maximise tourism's potential and problems?

I should also note that although my thinking has changed a lot in the duration of my master's candidacy, I do identify mostly with a centre right political policies and this have undoubtedly shaped the way I have approached the topic. Also I am a westerner looking into a non-western country citing and reading background literature predominantly by westerners so this thesis certainly does suffer (or benefit) from western bias. Also as an outsider asking questions to Samoan government officials, they have an interest in presenting their country in the best possible light. The Samoans are a proud people and extremely proud of their country. This may have led to interviews being less candid than they otherwise would have been.

In order to observe the research setting I stayed at Samoa's largest scale resort (Aggie Grey's Beach Lagoon and Resort) in February of 2008. This is an enclave style resort with a selection restaurants and services provided within the resort. It is designed so one does not have to leave the resort for the duration of a stay. The selection of large scale enclave style resorts is pertinent as they are one of the most widely criticised models of venture as they separate themselves from the local community, are designed towards meeting the needs of tourist; tourist expenditure is confined to the hotel and profits are then 'leaked' overseas.

In Samoa I met with various government officials associated with tourism (see below) went fishing and jet skiing with an adjacent beach venture (to observe the indirect industry) and ate at a variety of local restaurants both inside and outside the hotel. I also had the 
opportunity to talk informally with Fred Grey, General Manager for the Aggie Grey hotels. Fred is a business contact from my work and I had met him on two or three previous occasions.

During my time, a large cruise ship also docked which was also fortunate as I got to see some of the interplay between locals and tourists. At all places I visited I attempted to get a feel for interplay between the resort, the employees and surrounding communities. There are some Samoan government officials based in Auckland's Samoa House on Karangahape Road representing both investment and tourism. Interviews with these individuals were conducted prior to going to Samoa.

Meetings with government officials were summarised on note paper and permission was asked for the officials to consent to their opinions being published on behalf of themselves and on behalf of their department. Invariably they attributed the comments as their own rather than their departments or organisations with the exception of the deputy prime minister. These interviews were conducted in an informal conversational nature and structured around a list of catalyst questions. The questionnaire structure was only followed very loosely and when if a stream of conversation led elsewhere and was relevant, I did not stick to the original structure much at all. I tried to select interviewees from a range of different departments and it should be noted that the Samoan government was very accommodating in meeting my requests for interviews at very short notice. Whilst the Samoan culture is relatively informal and schedules relatively flexible, I would advise other students to at least make an attempt at setting interview times. I interviewed a representative from the Samoa Tourism Authority (STA) and my first stop was the visitor's bureau outside the parliament. I had already been given the name of Sonja Hunter CEO of the STA from my meetings at the Samoan consulate in Auckland and I used that as a catalyst for further contacts. Unfortunately Ms. Hunter was unavailable that week but I was able to interview 
another representative. At the end of each interview I asked which other departments and contacts would be worthwhile visiting on the basis on my research objectives and they were very obliging. For each department I visited I tried to interview the most senior person I could. This was based on the assumption that senior people had more of an overview approach and had a better grasp on wider issues outside their department.

The goal of the interviews was to get a better understanding of the research setting, to ask for additional written data and literature where applicable, to ascertain government perspectives on tourism development, to get leads for other interviewees and to provide support for some of the qualitative issues analysis.

The interviewees were as follows:

- Mr. Apete Meredith - Trade and Investment Commissioner

- Ms. Talei Lesa - Samoa Tourism Authority

- Mr. Fasitau Ula - Vice Consul - STA

- Anon - Staff Woman's Affairs and Community Development

- The Rt. Hon Telefoni Retzlaff - Finance Minister and Deputy Prime Minster

I have not attributed the quotes in individuals where unless I felt it was absolutely necessary. Tourism development is contentious and I did not want to see anyone disadvantaged in any way from participating in this research.As I was dealing with government officials, their English was mainly of an excellent quality although there were of a couple of gentlemen whom I tried to interview but I gave up due to language difficulties. 


\section{Chapter 5: The Research Setting}

The aim of this chapter is to discuss the unique environment of Samoa and explore issues and characteristics pertinent to Samoa which may play a role of the development of tourism.

\subsection{History, Culture and Religion}

At the turn of the century the Treaty of Berlin split the Samoan Islands into two parts, the eastern to America and the western part to Germany. Samoa was a German colony through to 1914 when New Zealand troops took over a German radio station there at the bequest of the British. From the end of the First World War through to 1962, New Zealand controlled what was called Western Samoa through a trusteeship.After repeated efforts by the Samoan people, Western Samoa gained independence in 1962 and signed a Friendship Treaty with New Zealand.

Travel writer Paul Theroux (1992) noted that there were marked differences between the societies in Samoa and American Samoa. In Samoa the inhabitants, although poorer in terms of material wealth, were more content and retained a keen sense of Samoan identity, while American Samoans retained some culture but integrated mostly alongside Western norms.

FaaSamoa is the term for the traditional Samoan lifestyle. FaaSamoa consists of the Samoan language, and customs of relationships and culture, that is a traditional and continuing Polynesian lifestyle of the Pacific Islands and Diaspora. This is completely understood by all Samoans, and provides support and direction. Fairburn- Dunlop (1994, cited in Scheyvens, 2005) cites this as a major reason why Samoa has taken a guarded approach towards tourism whilst other authors have argued that FaaSamoa has been an impediment to development. Jones (1991) finds that factors others than FaaSamoa have 
created impediments to development, most notably issues around access to prime land for tourism development.

Samoa has also a relatively ethnically homogenous society with 92.6\% Samoan (CIA, 2013) and as such is reasonably immune to ethnic inequalities and marginalisation expressed in Britton (1983) with respect to Fiji.

\subsection{Tourism Development in Samoa}

Samoa's history with large scale tourism could be said to have started with Aggie Grey's Apia hotel built in 1933. This hotel hosted American soldiers based around the region during the Second World War and is still a major landmark in Apia. However, in comparison to other Pacific countries around the region such as Tahiti, the Cook Islands and Fiji, tourism development to date has been approached very cautiously and slowly.

The Mau movement may provide some insight into the reasoning for this. During the 1920's a non-violent popular movement known as the 'Mau' arouse out of protest for the mistreatment of Samoan people. This is significant as the Mau also turned away from western development and culture (Stanley, 2000). This illustrates the historical ambivalence about tourism development by some Samoan people and is "strongly tied to Samoa's history of resistance to outside interference in country and culture... while Samoa faced 60 years of colonial rule they retained their cultural independence" (Scheyvens, 2005). Faiburn-Dunlop (1994) cited in Scheyvens, 2005 argues that FaaSamoa attitudes continue to mould the industry and she sites examples such as the withdrawal of a tourism advertisement which used a scantily clad woman as part of its tourism promotional efforts.

Active tourism promotion by the government did not begin until the 1990's when "they spurred on to find development alternatives after the devastation caused by two cyclones and taro leaf blight" (Fairburn-Dunlop 1994, cited in Scheyvens, 2005). The 
Tourism and Hotel Incentive Act was passed in 2003 with the express aim of encouraging more investment in higher class resorts. "This involves government playing a stronger role in assisting outsiders to lease land and tax breaks with the level of the break being proportional to the size of the investment" (Scheyvens 2005).

Focus on the industry gained momentum with a near doubling of tourist numbers from 48,000 in 1990 to over 88,000 visitors in 2001 (Page \& Lawton, 1996; Twining-Ward and Butler 2002 cited in Scheyvens, 2005). This grew to around 130,000 in 2010 (Index Mundi, 2010). Improved infrastructure including flights and tourist packages and political instability in Fiji should be factors which push this trend to continue although this may be mitigated through a general slowdown in the tourist source economies of the US and New Zealand. Almost all the Pacific countries have benefited in terms of tourist numbers from a slowdown in Fijian tourism. The non-Fiji Pacific small states have purported to have increased interest in both tourist activity and tourism FDI by up to one third. The Samoan authorities have taken advantage of this and put out the following press release in 2006 "Samoa is unaffected by the unfortunate unrest in some other South Pacific counties and visitors to Samoa can be assured of their safety and comfort” (Islands Business, 2006). The key carriers for Samoa are Polynesian Blue and Air New Zealand. Polynesian Blue is particularly significant as it is a joint venture between The Samoan government (49\%), Virgin Blue (49\%) and the owners of Aggie Greys (2\%). The establishment of Polynesian Blue in 2005 is particularly significant as it significantly increased the airline capacity and airline capacity is said to be a major determinant in incoming tourist numbers. Currently tourism contributes $25 \%$ to Samoa's GDP making it the most important sector of the economy (CIA, 2013). The peak season is in December which represents $15-20 \%$ of the years' visitors. Low season is in February. 
Scheyvens (2005) and Park (2003) have done some considerable work on showing the benefits beach fales provide to communities. Scheyvens in particular has demonstrated how they have been systematically ignored by some academics, non-governmental organisations, government officials and consultants. However, the beach fale as an alternative tourism product runs into problems as other alternative tourism products described and the jury is still out as to whether they are more pro-development than conventional tourism types. A key lies with community ownership and control as the assumption they make is that community ownership and control leads to better development outcomes for all.

The current tourism strategy has focused on large scale development signals a departure from the previous slow and cautious approach to tourism development where development limits were set at $5 \%$ per annum. The momentum seems to be growing. Having said this, the government has still exercised extreme caution in its vetting of projects and this will be discussed further in the next chapter.

These initiatives are critical in supporting this tourism growth as accommodation is currently limited although occupancy rates still remain at about 40-50\%. It should really be questioned then why Samoa should be building additional capacity when current capacity is being grossly underutilised. It is generally understood within the business community that there is a shortage of premium accommodation and even though occupancy rates are limited. It is assumed that the developments will attract more tourists and justify flights and vice versa. Having stayed at both Aggie Grey's it is clear that aspects the current infrastructure is not on par with other international standards for premium accommodation and development of these types of facilities may well bring in additional tourists who were previously put off but the lack of 5-star accommodation. Also, as Aggie Grey's is locally owned, it may not have the same degree linkages and access to external tourism system infrastructure as multinational chains and developers. The degree to which these developers have linkages and 
are able to take advantage of international tourism systems to drive increases in and decrease the variability of tourist demand should not be overlooked by the Samoan government and planners.

Scheyvens (2005) expresses concerns that accommodation figures do not contain fale style accommodation. It would be interesting to research what percentage of tourists would want to stay in fale style accommodations and whether tourists would prefer this style of accommodation over the more conventional to see how broad an appeal fales have as an accommodation option. Cohen (1972) notes that

Most tourists enjoy change and novelty only from a strong base of familiarity which enables them to feel secure enough to enjoy the strangeness of what they experience. Tourists like to go out only a certain distance for new and strange experiences but before these get extreme or prolonged, they shrink back to what they are familiar with, which may well be the carpeted air conditioned rooms or the typical home type meal. (Cohen, 1972).

A Tourism Development Plan (TDP) 2002-2006 was developed in line with this renewed focus on tourism and sustainable tourism is a key factor of this plan. "Sustainable tourism development will be taken at a rate and in ways that will

- Generate continuing economic benefits throughout Samoan Society

- Contribute to a general improvement in the quality of life in Samoa

- Reflect, respect and support FaaSamoa

- Conserve and enhance the country's natural and built environments Enhance tourist experiences of Samoa" (Pearce, 2002) 
Scheyvens (2005) argues that the 2002-2006 plan is reflective of a deeper commitment to sustainable tourism in contrast to plans from other countries which are more superficial and token in nature. She does however criticise the plan for its focus on larger hotel developments perhaps at the expense of beach fales. She also points out the government's efforts to help hotel and resort developers gain access to land could cause tensions in the future as land control moves out of communities. The land act of 2008 is a controversial one which will be discussed later in this chapter.

A criticism of the 2002-2006 plan from a Samoa Tourism Authority (STA) official was that the plan was too long and theoretical to be of practical use. This comment indicates there was a degree of tokenism to some aspects of the 2002-2006 plan. The new plan also suggests a growth rate in tourism of $5 \%$ to $10 \%$ where previous government documents had indicated $5 \%$. It should be noted that tourism in Samoa is off a relatively low base so percentage growth rates may seem relatively high when the absolute growth is maybe not that significant. Overall the plan supports a commitment sustainable development, a cohesive consultative structured approach to tourism development, better stakeholder participation and better training of locals both in terms of upskilling and expectations of tourist activity. Part of the plan involves STA officials performing road shows in villages both to educate locals on the effects of tourism and to gather feedback from communities. Of special note here is that Samoa gives enough focus to tourism development to do a plan specifically related to tourism. Being a small island with limited resources, there are not a lot of other development options available and tourism requires relatively little in terms of capital compared to many other industries.

One area of concern in the plan is the focus on the areas around Apia for tourism development. On one side, one could see this as positive as other rural areas are less 'contaminated' from tourism's ill effects. On the other side it could lead to a persistence of 
underdevelopment in areas outside of Apia and a persistence of marginalisation in areas of the periphery. Apia could also be subject to saturation and the increased activity may bring the city beyond its carrying capacity.

The Tourism Development (TDP) section in the 2008 Strategy for the Development of Samoa (SDS) departs to some extent from the 2002-2006 TDP with more emphasis in product development, marketing (to consumers and potential investors) and human resource development to support a $9.8 \%$ growth in visitor numbers. The assertion here is that growth of the industry will lead to benefits through increased employment, increased foreign exchange earnings and decreased reliance of agriculture, fisheries, manufacturing and construction "which is in decline after the hosting of the South Pacific Games." (Pearce, 2002). This is however in the context of the entire SDS 2008 document where the stated vision is "improved quality of life for all".

\subsection{Governance and Decision Making}

Samoa is a parliamentary democracy with a unicameral legislative assembly consisting of 49 members, 47 of who are Matai (chiefly titleholders) elected by citizens aged 21 years and over, and two of whom represent the part-Samoan and non-Samoan population. The Prime Minister selects 12 other parliamentarians to form a Cabinet. General elections are held every five years. The Human Rights Protection Party (HRRP) has been in power for an uninterrupted 23 years. The 1990 Village Fono Act gives village councils authority over village law and order, health and social issues. The constitution was established in 1960 and blends traditional and democratic institutions and processes and recognizes the separation of powers; legislature, judiciary and executive (SDS 2008-2012). Of particular note here is the representation of the Matai in the legislative assembly who are also village leaders at the community level. This gives a level of community representation 
and linkage in government which is stronger that of most parliamentary democracies. The March 2006 elections were again won by the HRPP by an even larger margin than 2001 although there have been increasing frustration with some government decisions of late, most notably the decision to change the side of the road cars drive on.

\subsection{Land and Land Tenure}

Land is of critical importance to tourism development as it is one of the levers that Samoa has on a national and village level to negotiate more preferable development outcomes for the host country. It is also of critical importance because of the central role on land in Samoan culture in similar vein with indigenous peoples throughout the Pacific. Adaptancy platformists contend that large scale tourism projects will pose a threat to local land tenure and security where alternative projects will reinforce this security (Adams et al., 2005). On the other hand tourism development in Samoa has been stifled by landowners who refuse to release control of their communally held resources (Scheyvens 2005).

Around 80 percent of land is communally held customary land with the remainder being Government and free hold. Most of the coastal land best suited towards tourist developments is customary and developers are able to access this land by way of 30 year leases. These leases are subject to feasibility and impact studies and must be approved by the Minister for Tourism, Minister for Lands and Survey and the Prime Minister. Decisions on the land are made by generally by village consensus and includes village members who overseas. Although the Matai have control of the land and can make decisions without consensus, they have a serious responsibility to maintain family peace and harmony.

The consensus process can therefore be lengthy and problematic. From information I gathered from interviews with the STA the process is now purported to take no more than six months. Also, attempts to bring in big hotel chains flopped when landlords started to haggle for more money. This can act as a major disincentive for investment in large scale tourism 
and make development difficult as projects are diverted to other countries, and banks and lending institutions either charge prohibitive rates of interest to compensate for project risk or are reluctant to lend at all. The government is making efforts to make the application process more streamlined in terms of bureaucracy and access to land. This is already bearing fruit as there are major development projects in the pipeline. Therefore land tenure seems to have been a major issue for foreign investors (Scheyvens, 2005).

Scheyvens (2005) expresses concern over the loss of control of the land from indigenous communities asserting that control leads to better development outcomes for the community. Park (2003) describes a tension within villages where the Western norms of individualism are creeping into Samoan society and this is affecting Matai with regards to decision making and allocation of land for particular uses. Park (2003) contends that the difficulties in land are actually of benefit to Samoa as it gives the Samoans greater control of tourist activity and has assisted in controlled growth of the industry.

As land is communally owned, it does pose issues for using this land for collateral securing loans for entrepreneurship (Arutangi \& Cocrombe, 1987).

No alienation of customary land - It shall not be lawful or competent for any person to make any alienation or disposition of customary land or of any interest in customary land, whether by way of sale, mortgage or otherwise howsoever, nor shall customary land or any interest therein be capable of being taken in execution or be assets for the payment of the debts of any person on his decease or insolvency.

Samoan Constitution: Section 102

Therefore, intervention is required at a governmental level (Samoan and foreign) to underwrite small personal business loans so entrepreneurs can access capital take advantage of the potential tourism has to offer. 
In June 17, 2008, the Land Titles and Registration Act 2008 came into effect and has caused considerable controversy. The act in summary provides the Torrens system to freehold land (Ministry of Natural Resources and the Environment, 2008). The Torrens system is a system of central registration. The benefit of the Torrens system is it does not rely on the status quo system of titles which is only as strong as the weakest link and is subject to uncertainty. The act presumably helps to facilitate tourism development by talking out some of the previous uncertainty and bureaucracy regarding the previous system. However considerable outrage to the act ensued as people saw this act as a threat to customary land tenure and possible alienation of customary land. However, the government went to pains to point of that this did not apply to customary lands which was covered by the constitution and other acts (Tupufia \& Hazelman, 2012). This shows the considerable ties and passion that the Samoan people have for their lands and for customary tenure. It also demonstrates the underlying tension between the sometimes competing objectives of tourism development and faaSamoa.

Butler (1992) uses the law of commons to argue the communal ownership of land may present issues for on-going sustainability of tourism projects. As tourism develops, it is also likely that western influences will penetrate Samoan society will become increasingly individualistic (Fiske 2002). Both these factors look set to challenge the communal nature of land ownership at some time in the future.

\subsection{Economic Development}

Economic development poses special challenges for Samoa given its small size and limited resources.

Small Island Developing States and the islands supporting small communities are a special case for both environment and development. They are ecologically fragile and 
vulnerable. Their small size, limited resources, geographic dispersion and isolation from markets, place them at a disadvantage economically and prevent economies of scale. (UNEP 1998)

Given the above, tourism seems to be the logical development tool of choice small island economies. Offset against other industries, Samoa lacks the economies of scale for most forms of manufacturing plus its isolation from other markets makes freight considerably more expensive for prospective importers. The South Seas meat packing plant in Samoa is a classic example of Samoa playing in an industry where it lacked comparative advantage due to limited size and this plant is ultimately failing. In comparison to other industries, tourism is seen to be more ecologically sound (UNWTO 2004). One only needs to visit the Star-Kist tuna canning factory in American Samoa to see some of the environmental effects of that industry on a relatively small island nation.

Relative to alterative tourism types while both type of tourism can be of benefit to communities, alternative tourism by its nature lacks the scale of tourists and therefore limits potential sources of revenue. By doing this employment opportunities are lost through both direct employment and employment through ancillary industries.

Employment is of particular concern as Samoa is a country of excess labour.

Currently there are workers from Samoa who go over to American Samoa to work in the tuna factory. These workers stand to benefit from large scale tourism development as it will push demand up for the current labour pool and increase the wages of those who work at the tuna factory assuming there is some overlap in the labour demand. Many people may also decide not to work at the tuna factory and choose employment in tourism instead. This will save many people the long and sometimes dangerous journey across to American Samoa by ferry. 
They will have less time abroad and more time to spend with their families. Also conditions working in tourism ventures are arguably much better than working at a tuna factory.

Prior to tourism becoming the biggest industry in Samoa, the largest source of revenue was remittances. On one hand one could tourism and employment is more dignifying more beneficial and less 'dependent' than relying on remittances from overseas. Bertram (2004) argues otherwise stating in his analysis of Migration, Remittances, Aid and Bureaucracy (MIRAB) that remittances from Samoan diaspora are essential for the diaspora to retain linkages with village life and the homeland. Employment is often argued as a precondition to self-esteem and conventional tourism advocates often cite employment as a major benefit (Hartley. 2011). Even if locals are employed as porters or chamber maids, this does not necessarily mean they cannot take great pride and satisfaction in their work (Cukier 2002)

\subsection{Local SME Development}

There are already several SME which are struggling due to the lack of tourists on the island (interview). As suggested in chapter two, the development of mass tourism can help to accommodate alternative as well as small enterprises though improving the transportation link. An increase in tourist numbers creates bigger markets for these enterprises.

Milne (2005) describes severe gaps in the capabilities of current SME tourism owners and operators in the South Pacific generally. Terra Firma Associates (2001) cited in Scheyvens (2005) points to a lack of business know how by fale operators. The government here needs to intervene temporarily as the local population does not currently have the skills to effectively to take advantage of opportunities. Intervention should take place in terms of training programs for local entrepreneurs and assisting with access to capital. NGO's and 
NZAid could also look to assist here as well and NZAid's possible role will be discussed in more detail later in this chapter.

Land may also play a significant issue in SME as the problems discussed in Park (2003). She describes difficulties in getting access to land for building beach fale for families who are not in the immediate family of the Matai. five of the six beach fales she visited were owned and operated by immediate families of Matai and the one that wasn't had poor land location. The same problems described here will also be applicable for the development of other SME tourism ventures where land is required.

The STA does have training for beach fale owners and has created a beach fale operators manual while SBEC and the Tourism Support Fund can help owners access funds (Twining Ward -1999 cited in Scheyvens, 2005) This will go some way towards the addressing the significant gaps in capability and know how (Scheyvens 2005) but based on Milne's (2005) work, gaps still exist so more must be done to address the shortfalls. Milne (2005) also points to South-Pacific Travel's Enterprise Tourism toolkit as a possible source for training. It is also possible that by having more tourists on the island, the locals will have more exposure and learn from their domestic competition. An individual working as an employee at one of the larger hotels observes the format and initiatives of his larger institution and takes some of his learning back to his village where they are operating beach fale. The government may also want to consider training levies or more formalised structures where locals can learn off their larger domestic competitors. The Samoa polytechnic also has courses in hospitality and tourism.

Park (2003) also found a general attitude among Samoan operators where there was an expectation that as it was the government promoting tourism, the government would provide everything. It needs to be made clear that the onus needs to come from the individual 
operators and this can be part of more intensive training programs for locals. Obviously the ventures are not going to be successful if operators rely on the government alone.

Large tourism projects will also aid SMEs including alternative tourism projects in terms of infrastructural development. Scheyvens (2005) bemoans a lack of roading, water and electricity in the Northwest of Savaii which she says is impeding the success of fales in that area. In reality, infrastructural development in that area would only occur in the case of a large tourism project. Such a project would have benefits for adjacent sites that would then be able to access the same infrastructure making their projects much more attractive to tourists.

Rather than seeing alternative tourism as the antithesis to conventional tourism, the latter can actually support the former in many instances and the former can in fact be very dependent on the success of the former as discussed in the literature review.

\subsection{Cultural Degradation}

Critics often express concern over cultural bastardisation and degradation, for example Lea (1988) in his reference to the 1962 movie Mondo Cane. Park (2003) and Scheyvens (2005) have both concluded that government concerns over cultural degradation were somewhat misplaced at a fale level as locals were happy to welcome tourists onto their fale and welcomed the interaction and exchange resort. Furthermore they felt a sense of pride in showing off their culture to outsiders. Scheyvens (2005) does point to some isolated incidences of debaucheries drunken tourists or payment issues however; these instances were in the minority.

\subsection{Natural Disasters}

Each year from 1989 to 1993 Samoa was hit by severe cyclones. The worst being Cyclone Val in 1992 which defoliated $90 \%$ of the island and destroyed about half of the 
islands coconut trees, which ultimately had a detrimental effect on the country's economy. Cyclones of this severity are, fortunately, unusual. The cyclone season is usually between January and March. There is currently some debate about whether this is likely to change because of a perceived permanency to the Southern Oscillation of the El Nino effect. The Pacific is one of the most tectonically active areas of the world, being surrounded by the Ring of Fire and having numerous volcanic islands scattered across it. Compared to most areas in the Pacific, Samoa is relatively quiet (Samoan Sensation, 1998)

In event of the above multinational corporations (MNCs) have the diversity of investment and access to insurance to overcome such events, to continue operations afterwards and to assist in the clean-up efforts. Whilst the above is not compulsory, the capacity for the MNC's to help is the greatest and it is hoped they will voluntarily even if the short terms costs to the company are adverse. For example, in late 2009 a tsunami hit Samoa killing 119 and leaving many more homeless. Aggie Greys Hotels provided temporary food and shelter for those left homeless by the disaster.

\subsection{Summary}

The unique social, cultural, political, geographical and economic environment in Samoa presents unique challenges for large scale tourism development and all of these factors need to be taken into account for policy initiatives and recommendations. Issues around land seem particularly problematic as it seen as a barrier to progress but attempts to liberalise have been met with scepticism and resistance. For tourism development of any scale to be successful, an understanding of the local environment is essential for its success. 


\section{Chapter 6: Results and Discussion}

As outlined in the methodology the main thrust of the results section was supposed to be analysing results from an impacts survey. Unfortunately, the survey could not be completed as discussed in the methodology. Even without the results however, I believe there is enough from the literature review in itself to warrant a rethink of large scale tourism by development specialists. As the research for this project rested largely on the survey, the secondary objectives of evaluating government views and policies on tourism as well as a review of the latest development plan will be emphasised more.

\subsection{Government Policy on Tourism}

In interviewing government officials there was a wide range of perspectives which mirrored to a large extent the same perspectives found in literature. Interestingly there was not anyone who took that perspective that tourism itself was negative as they all agreed the industry had the potential to help Samoa. The perspectives from the different departments also reflected to some extent the nature of the departments.

Deputy Prime Minister/Finance Minister, Trade Commissioner and STA representative were strong advocates of tourism including large scale.

“Why shouldn't a large percent of profits be allowed to go abroad. The companies have taken the risks. And our communities have very little and tourism will give them jobs. Surely this something is better than nothing. Some of our guys have nothing otherwise." Interview

“Tourism allows massive employment opportunities, especially for non-skilled workers" Interview 
"Whole spectrum - across the board. Flexibility in market access and infrastructure." Interview

"I have a case where a local needs to have four people on his boat to make his venture economically viable. If he doesn't have four then he doesn't go out and if only three people book then they don't want to pay more. Developing mass tourism will help make sure he gets his four people. " Interview

"We are not all selective about the applications for tourism permits that we get...we want to promote all types of tourism" Interview

"After we get the first projects, the subsequent projects will be much easier and we can be more selective. One of the biggest impediments is lack of trained staff and after we get a few projects we will have a trained pool of labour available as the first few projects will do a lot of the training."

"We really want to push all types of tourism because of the employment it creates...otherwise there are guys who would just lay around the home and start making trouble" Interview

"It gives them something at least because right now they really have very little" Interview 
"We think we can counter issues such as prostitution and drugs with education programs" Interview

The STA commissioner although a supporter of tourism advocated a more cautious approach:

"The slow scale of development to date has been like a blessing in disguise, we have not had much change to our culture and traditions" Interview

"Because our application processes are a little more difficult, it tends to only attract the investors who have a real interest in Samoa and weeds out some of the rogues" Interview

Whereas the representative from the ministry of women, community and social development preferred smaller scale initiatives as she felt:

"the benefits stay within the community" Interview

Where it would be wrong to see the government as one large homogenous entity in its views on tourism development, overall the Samoan government does seem to be in favour of some large scale tourism development and a belief that problems around large scale developments can be mitigated. This is consistent with what has been said in literature where government and business are generally supportive but may be at odds with the general populous and Non-Governmental Organizations (NGOs) (Hall, 1994) This may be due to the prestige which come with high profile projects (Sharpley and Telfer 2002). 


\subsection{Tourism FDI into Samoa}

Foreign direct investment (FDI) is governed by the Foreign Investment Act 2000 which requires all foreign investment projects to obtain a foreign investment certificate from the Ministry of Commerce, Industry and Labour (MCIL). The tourism sector currently only comprises only $12 \%$ of foreign investment which is disproportionably low given the sectors contribution to the economy is over $25 \%$. Local equity participation is encouraged by the government although not mandated (Interview). The government has taken several measures of late to encourage FDI, namely decreasing the bureaucracy and making access to land easier as discussed in the previous chapter. They have also made the application process a one stop shop process where in the past applicants had to apply across different departments (Interview). The trade and investment commissioner to New Zealand has made significant movements in his FDI promotional activities by attending key seminars and networking with key players in the industry based in New Zealand (Interview). These promotional steps will lead to significant new investments (Interview) and we are already seeing the fruits of the promotional activity with several new foreign owned projects in the pipeline.

The key issues here are around foreign control and the implications of foreign control for Samoa and for development. Foreign operators bring with them capital, skills and knowledge from overseas regarding tourism operations, skills which can be transferred to the local population. It is likely that many locals will be put through training programs by large tourism enterprises. Former employees setting up competitive enterprises following employment at a large tourism venture have a better chance of luring tourists to their operation. However, this starts to blur the line between setting up ventures which cater to western preferences and tastes and local ventures which are suited to the preferences of local culture. The two need not be mutually exclusive and each village needs to find a balance suitable for them. 
MNC chains such as the Hilton, or Hyatt or Warwick in particular also have significant marketing power through their contacts and networking with travel agencies and their global marketing campaigns and infrastructure. Through this they would be able to attract more tourists to Samoa by reaching more potential tourists than a locally owned venture could. As discussed in the literature review they some risk out of tourist visiting Samoa as chain hotel brands have minimum brand expectations and some tourists will only stay at brand hotels because of this. Without chain hotels, there is a significant segment of the tourist market which Samoa would be missing out on. In event of a downturn in Samoan tourism, a multinational which has a diverse number of operations can sustain a downturn in operations and take a longer turn approach whereas a local operation may be forced into insolvency.

In Samoa each application is considered on a case by case basis so officials can make this decision on a case by case basis and perhaps reject applications from chains with poor reputations. As part of the application process, officials can also impart information about Samoa to steer developments in ways more fitting with the local environment. It is in Samoa's interest to find the balance between not putting investors off and also not attracting the less scrupulous short term, more speculative investors. Samoa is a very small island on the periphery and as such can only take in a limited number of tourism ventures. Background checks on investors other operations can be useful practice.

Samoa must be able to cautious of attempts to any liberalise the application process given the limited amount of land and therefore the limited number of developments that can be approved. The FDI application process affords Samoa a degree of protection to ensure that there is a good fit between the developer and host country. 


\subsection{Ministry of Women, Community and Social Development}

In 2003 the Samoan government established the Ministry of Women, Community and Social Development (MWCSD) to ensure that policies, strategies and activities are all integrated for the benefit of families, villages and communities in Samoa (MWCSD). First and foremostly this shows a commitment by the Samoan government to address social issues along the development pathway. The plan includes measures for tracking on monitoring development of the potentially disadvantaged groups of youth, elderly and women as well as training schemes.

This type of intervention is critical as the literature shows that under a neoliberalist paradigm that marginalisation is likely without some kind of intervention by government. In addition the measure for training schemes is critical as the literature suggests that currently Samoa and it would be logical to assume marginalised groups in particular, lack the skills to be able to take advantage of tourism's benefits.

\subsection{Community Participation}

The Samoa Tourism Authority runs a regular road show to meet with villagers and their objectives are twofold. Firstly in inform locals of anticipated changes in the industry and potential changes for them. The second is as a feedback mechanism for both proposals and issues that they are experiencing at the grass roots level.

The feedback mechanism is incredibly important as it gives communities a say in tourism policy development and alerts the STA to issues in communities. Milne (2005) points to limited community participation generally in the Pacific. However, with the Matai structure of governance and the feedback mechanism described above, Samoa seems to be doing better than their regional partners in this respect. Care must be taken as we have established that there is a wide range of views within communities. There is a danger that the 
feedback process gets dominated by local elites, in Samoa's case, Matai, family of Matai and men generally. The STA must take care to solicit views from a wide spectrum of stakeholders. This may involve having to talk to some people under condition of anonymity as they may not be comfortable speaking out in a public forum or environment.

From the stakeholders standpoint they have a responsibility to try to understand the plethora of issues with respect to tourism asking questions to the STA if required. If this is not done, then the feedback process is undermined as locals fall prey to rhetoric and superficiality without understanding the issues. The government must also take feedback from the community seriously as there is a danger than this process runs into tokenism. The population must be seen as a partner rather than subjects being dictated to. Through the backlash of the 2008 land proposals and protests over the proposal to change the side of the road Samoans drive on, the local population have already shown themselves apt at opposing legislation and proposals which they do not consider to be beneficial.

\subsection{Marketing}

Samoan Tourism Marketing activities are primarily conducted by the STA. The aims of marketing activity are for the enhancement of tourist numbers and setting an appropriate 'brand' for Samoa. The numbers enhancement role of the STA is reasonably straight forward. More tourists equates to more revenue and more multipliers. The STA can use promotional efforts to control the numbers coming to Samoa and pull back on activities if issues raise or carrying capacities or target growth rates look to be exceeded. To enhance tourist numbers significant efforts have been performed recently to establish linkages with travel agencies, especially in the key markets of Australia, New Zealand and American Samoa. The STA and representatives from hotels and airlines meet fortnightly to discuss possibilities for joint promotional activity. 
The STA is also responsible for the 'Branding of Samoa'. The branding is particularly important as it sets the culture for the tourist activity, the type of tourist who is drawn to the message and defines to some extent the linkages with the environment outside of resorts. Samoa is promoted as "the heart of Polynesia" focusing on the culture of Samoa as a key selling point. Tourists are much more likely to venture outside of their hotels and form economic linkages with industry outside that of resorts. Within Aggie Greys the city of Apia and tourist activity such as the local markets and entry onto local villages were heavily marketed. Buses taking tourists into town leave every half hour. Contrast this with say Fiji's Denerau island where activities are relatively self-contained and promotion is more skewed towards other activity on the island. In the former case SMEs are more likely to benefit from tourist activity multiplier enhancement and leakages reduced. Park (2003) and Scheyvens (2005) have already shown that local population interaction with Westerners doesn't seem to pose any major significant issues.

The government can influence this by the type of developments they approve and by suggesting modifications to current proposals. Also as this is the dominant message marketed by the STA, proposals from investors are more likely to 'fit' the message. The uniqueness of the message also put Samoa in good stead as it gives then differentiation in a competitive marketplace. Purely competing on sun and surf can lead to excessive price competition and less consumer loyalty. The path that Samoa has chosen to market their products shield's the industry to some extent from currency and mass fluctuations in demand and price. From a dependency perspective this unique approach leads to a better bargaining position for Samoa so it does not have to succumb to as much to liberalisation and tax incentives in order to compete with other destinations for capital projects. 


\subsection{Case Study: Aggie Grey's Lagoon and Resort}

I will take the example of Aggie Greys Beach Lagoon and Spa to demonstrate the potential economic impact of a large scale tourism project to Samoa. The 140 room resort employs 100 plus people although unfortunately they were not willing to divulge any information regarding pay rates. I should note that observationally the employees around resort looked relaxed, friendly and happy. In this instance the land is freehold and owned by the Grey family as a family run business. In most cases, as most tourism prime land is customary owned and will be leased out, there is a windfall in terms of a steady income stream for the community for the lease of their land. This money can be used as seed capital for other ventures, for other village based projects or for spending in the community. For the above, there is a clear multiplier factor as tourists come into the country and stay the hotel and spend money on activities and purchases. The money stays in the local economy through wages for the 100 plus staff, interest to local banks, taxes to the government, payments to suppliers and profits to the Grey family.

Leakages would come in the import of supplies and in the case of foreign ownership the profits would likely be remitted back overseas. For imports of supplies although there is a leakage component, what is overlooked is the domestic component of the import of that product. If a product is imported, it relies on domestic customs, clearance, distribution, warehousing and salesmanship. So there can be key linkages with the domestic economy even if something is imported. There are many things are would be difficult to import such as fresh produce which would be demanded by the larger tourist destinations. These industries will thrive with greater tourism development as it has in Fiji in the case of the avocado industry.

One of new Warwick projects is purported to be a 300 room project employing 170200 staff so it can be assumed that the economic advantages from Aggie Greys could be 
reasonably doubled. With the Warwick, there would also be the initial capital injection into the economy with construction workers being employed from the outset. However any profits the Warwick makes from its normal operations can reasonably be expected to go offshore although a portion of that will be reinvested into the local economy for upgrades and maintenance.

The development of the internal economy will have other significant flow on benefits. One of these is lessening the numbers of the best and brightest leaving the country due to the brain drain phenomenon. The opportunities available to them are increased and this in turn increases the productivity and prospects for the country. Also with more money in the economy the savings pool can be expected to increase giving SME's better access to capital. On the reservations desk at Aggie's Greys, the city of Apia, the local markets and village visits were heavily marketed. Many villages also charge tourists for visitation rights and for each photo they take on customary land.

During my stay at Aggie Greys, I had an opportunity to view a cultural show and I spoke informally to some of the participants afterwards. They showed the same sense of pride in displaying their culture despite the differences in environment where they displayed their culture. Hotel employees also seemed to show the same sense of pride on a national level welcoming tourists to their nation as villagers showed welcoming foreigners to their fales. Park (2003) suggests that that with fales, locals are welcoming tourists onto their 'environment' whereas with mass tourism this is not necessarily the case. However, anecdotally the Samoans seems to display the same sense pride irrespective of the fact that this wasn't their 'environment' as it was still their country. 


\subsection{Samoa Tourism Development Plan 2009 - 2013}

The mere fact that the Samoan government has chosen to develop a plan demonstrates a commitment to some kind of sustainable development and an overarching plan. Sharpley and Telfer (2002) state that an overarching plan is critical to the development of tourism as public physical infrastructure such as airports and sewage feed into plans from the private sector. In addition, legislation such as that affecting land leases/ownership must also be addressed at a governmental level. The new plan presents a departure from the previous plan as being much more pragmatic in nature. One STA staff member lamented the previous plan was "too long" and lacked pragmatic actionable items.

The plan starts with a broad overview of the tourism sector in Samoa and its vision for Samoan tourism. What is interesting from this initial overview is whereas the TDP states the need for foreign capital investment and catering to the demands of an increasingly competitive external market forces, it also explicitly sets out to exclude mass tourism.

Importantly, whilst Samoa is decidedly seeking significantly increased volumes of visitors over levels currently being achieved, Samoa is not seeking what in world terms can be regarded as mass tourism. Indeed, on the contrary, there is concern to ensure that the quality of life and the Fa'a-Samoa are not in any way prejudiced or imperiled by possible downside risks of mass tourism. (Samoa Tourism Authority, 2009).

While this initially seems in two minds, it is clear that the government does not intend to adopt the Adaptancy Platform as foreign investment and external modes of tourism are actively encouraged. Thus the above can be interpreted as taking a cautious approach to taking on some conventional tourism by a rejection of a neoliberal free for all marketplace. Arguably you could say that the Samoan government has taken on the Jafari's Knowledge 
Platform. The government intends to take on several different types of projects including "a few" large projects and this way it can have a diversified base of products to help avoid exposure and vulnerability to one type of tourism.

A theme which pervades in the overview and throughout the document is the importance of the branding and positioning of the "Samoan Experience". It is clear that Samoa wants to differentiate itself through it marketing and thus avoid both the lower margins of the price competition in the sun, and surf markets and the necessary concessions which would have to have been made at a national level. Instead the Samoan culture is emphasised though the friendliness of the Samoan people and experiences with Samoan cuisine, tropical fruits, Samoan architecture. This is critical not only for avoidance of low margins and improving Samoa's negotiating position but also for the linkages it provides in terms of opportunities for local business and employment of locals.

The next section outlines key benefits from tourism development, with the multiplier effect and infrastructure development and employment. Of note is also diversification where tourism is seen as an insurance for the economy against the traditional base of agriculture and fishing. Also of note is the claim that tourism can help to preserve the culture, heritage and environment by highlighting the need for sustained management.

This can be seen in the villages where a fee is being charged for entry and taking of photographs. Villagers will see the connection between upkeep of the land and more fee paying tourists coming and will therefore have a self interest in maintaining their land. Deforestation has also been seen as a major environmental threat and tourism is seen as an alternative source of income as well as a reason to maintain the trees to preserve the natural landscape for tourists.

What is perhaps missing in the justification of tourism is further analysis of the multiplier effect to take into account leakages. It is assumed in the analysis that direct 
spending by tourists and the multiplier effect would be beneficial whereas more detailed investigation in this area is required. Another strong theme throughout the plan is the need for educational programmes and consultation. The government believes that much of the local scepticism towards tourism can be overcome if locals have information about the issues surrounding the tourism sector.

Open consultation and communication will lessen the likelihood of conflict arising between residents and the tourism sector. Local residents need to know how tourism affects their lives - the benefits, quality of life factors and the direction being taken to develop the industry. Community education, information forums and opportunities to transfer a greater understanding of the industry's work to community members are essential in tourism development. (Samoa Tourism Authority, 2009).

The next section has government reiterating the disadvantages found in literature regarding small islands on the periphery citing limited resources, limitations of access and connectivity and tyranny of distance. This demonstrates a good understanding of the tourism environment by the planners. The area of human resource management is another strong theme which pervades throughout the document and there are plans for programmes and scholarships to assist in developing the capabilities of the host nation. This shows that the planners have an understanding of the shortfalls in the capabilities of the current workforce and that for Samoa to take advantages of tourism's potential (Liu \& Wall, 2006). Of special note is both vocational and managerial training programmes are proposed so locals will build capacity to be managers as well as workers.

The TDP also highlights the focus of the following geographical areas for tourism development (and infrastructure development):

- Apia (Vaimauga West, Central Apia, Faleata East and Faleata West) 
- North Western Upolu (Faleolo, Mulifanua, Manono Uta, and Falelatai)

- South-east Upolu (Aleipata Itupa I luga, Aleipata Itupa I lalo, Lepa, Lotofaga and Falealili)

- Southern Upolu (Siumu, Safata, Salamumu, Lefaga and Falease'ela)

- Eastern Savai’i (Faasaleleaga I, Faasaleleaga II, Faasaleleaga III and Faasaleleaga IV)

- Northern Savai’i (Gagaaemauga II, Gagaaemauga III, Gagaifomauga I and Gagaifomauga II)

- North-west Savai'i (Alataua West, Falealupo, Vaisigano East and Vaisigano West)

These areas are the ones which already have significant activity and are ones which already have some level of tourism. They are also the areas purported to being open to change and development. One of the issues with this strategy is the possible marginalisation and lack of infrastructure development in areas outside of these seven areas and increasing inequality with these seven areas and the rest of the country. Strategies must be adopted by the Samoan government to address a level of distribution to these marginalised areas so they can partake in some of the benefits of tourism development.

The planners also mandate a number of indicators and impact reports both social and environmental to ensure development is occurring sustainably and benefits are reaching the host populations. A research based approach is emphasised through the document. “Continually well researched and informed and strategically focused for optimum outcomes for all stakeholders.” (Samoa Tourism Authority, 2009). The TDP states that previously environmental issues were addressed in an adhoc manner but the establishment of the Ministry of Natural Resource and Environment puts these issues under one banner where issues can be prioritised, databased and dealt with systematically using a coordinated approach. 
The World Tourism Organization (UNWTO) mandates the use of indicators which can be periodically measures so corrective action can be taken. The UNWTO suggests the following indicators (UNWTO, 2004):

- Early warning indicators (e.g. decline in the number of tourists who intend to return)

- Indicators of Stress on the system (e.g. Water shortages or crime indices)

- Measures the current state of the tourism industry (occupancy, tourist satisfaction)

- Measures the impact of Tourism Development on the biophysical environment

- Measures of the management effort - e.g. clean-up cost

- Measures of the management effect, results or performance (e.g., changed pollution levels, greater numbers of returning tourists)

Samoa already has most of these systems in place. The mainstay of the Samoan environmental strategy is the Environmental Impact Assessment. Each major tourism proposal needs to undergo an environmental impact assessment (EIA) to assess predicted levels of benefit as well as social and environmental degradation. The government has strict thresholds in place for the approval of projects and projects will be denied or require modification if these thresholds are not met. Once projects are in place, the government has monitoring systems such as the measurement if key indicators by the National Department of Statistics/STA and the STA feedback groups which go out visiting villages.

Some smaller alternative tourism fale projects have been bypassing EIA assessment and monitoring processes leading to ad hoc development and unforeseen environmental damage where larger projects are party to EIA and structured monitoring practices. In this respect the conventional projects can be more structured and accountable than smaller alternative tourist projects. 
For both social and environmental degradation, the carrying capacity of Samoa comes into play. The carrying capacity is defined as the point where the country starts experiencing negatives utility from the addition of tourism product. The UNWTO (2004) has stated that this is both a qualitative and quantitative measure. The feedback and monitoring system mechanisms in place will help the STA determine at which points the carrying capacities have been reached.

Throughout the document communication with stakeholders and the populations is a major theme. Although Samoa is disadvantaged in many ways due to its size, the small size and population, it does make two way communications with the government much easier. The government seems committed to establishing these communication networks both to inform the populous about projects and the potential benefits and also for soliciting feedback. This way it can seek to avoid misunderstandings and scepticism as well as tailor initiatives to address issues from the stakeholder feedback.

\subsection{Summary}

Overall the Samoan government's approach to tourism seems cautious but yet considered. It sees the benefits it can gain from large scale tourism projects but has a good awareness of the potential issues and has plans to mitigate the potential problems. It has the necessary environmental and social impact indicators to make sure that tourism is occurring sustainably and to address issues that may arise during development. The commitment to sustained two way communication with stakeholders which is expanded to include all of Samoa is commendable and realistic given the size of Samoa. The exposure to a variety of tourism projects including large scale seems astute given the potential for seasonality and fluctuations in demand. 


\section{Chapter 7: Conclusion}

At a theoretical level there is huge controversy over the value of conventional tourism to development. On the one hand you have cautionary and adaptancy theorists who dismiss the ability of large scale development to contribute to development and on the other hand you have advocacy and knowledge platformists who purport large scale tourism's ability to benefit. Given that the initial research for the cautionary and adaptancy theorists was over 20 years ago and major issues emerging with small scale alternative tourism it seems an opportune time to re-examine the value of large scale tourism in a scientific manner devoid of ideological bias.

Samoa as a small island in the pacific with a homogenous, indigenous population with a very traditional communal way of living presents a unique environment and unique challenges for the development of large scale tourism. Large scale tourism development in Samoa holds great theoretical promise in Samoan development, in terms of poverty alleviation, creating employment and therefore self-esteem, creating better work condition and enlarging people's choice variables. The Samoan government who are supportive of a few large scale projects has taken a very cautious and informed approach to tourism development and make proposals such as the development of workforce capability at worker, managerial and entrepreneurial levels to make sure the host population has the best opportunity to benefit. In addition, it's marketing of Samoa's unique culture and the promotion of cultural activities and products with strong linkages to the local economy add to Samoa's strength in the global marketplace and provide opportunities for the local population to benefit.

New research focusing on large scale developments in Samoa and elsewhere is recommended as the current attention on alternative tourism alone presents limitations of scale and presents its own set of problems and issues. 
All of my analysis has been performed using my worldview which is undoubtedly western and somewhat orthodox. Any understanding of FaaSamoa I have will undoubtedly have its shortcomings as I am not Samoan. Although I have done my best to understand the nature of this phenomena there is still a chance I have severely misinterpreted its nature or under or overestimated its impact on Samoan society. 


\section{Glossary}

EIA - Environmental Impact Assessment

FaaSamoa - Samoan way, belonging to Samoa

Fale - House (Traditional)

Matai - Title Head of an Extended Family

MNC - Multinational Corporation

MNRE- Ministry of Natural Resource and Environment

NDS - National Department of Statistics

SME - Small Medium Enterprises

STA - Samoa Tourism Authority

UNWTO - World Tourism Organisation 


\section{References}

Adams, E., Beck, K., Picon, D. \& Wickoff, A. (2005). Gateway to the Mayan world: An assessment of counterpart international's community development \& sustainable tourism project in Chisec, Guatemala. Final Capstone Project.

Arutangai, S. \& Crocombe, R. G. (1987). Land tenure in the Pacific. University of the South Pacific.

Altman, J. C. \& Finlayson, J. (1992). Aborigines, tourism and sustainable development. Centre for Aboriginal Economic Policy Research, Discussion Paper.

Babbie, E. R. (2012). The practice of social research. $13^{\text {th }}$ ed. Belmont, CA: Wadsworth, Cengage Learning.

Beeton, S. (1998). Ecotourism: A practical guide for rural communities. CSIRO Publishing.

Berger, A. A. (2004). Deconstructing travel: Cultural perspectives on tourism. Walnut Creek: CA, AltaMira Press.

Bertram, G. (2004). The mirab model in the $21^{\text {st }}$ century. Islands of the World VIII International Conference, 1-7 November.

Blackman, S. (2011). Business schools blazing trails in social impact management. Retrieved from http://www.usnews.com/education/blogs/MBA-admissions-strictlybusiness/2011/10/07/business-schools-blazing-trails-in-social-impact-management

Britton, S. (1983). Tourism and underdevelopment in Fiji. Australian National University Press.

Brown, D. O. (1998). In search of an appropriate form of tourism for Africa: Lessons from the past and suggestions for the future. Tourism Management, 19(3), 237-245.

Bryden, J. (1973). Tourism and development: a case study of the Commonwealth Caribbean. Cambridge University Press 
Butler, R. (1990). Alternative tourism: Pious hope or Trojan horse? Journal of Travel Research, 28, 40-45. DOI: 10.1177/004728759002800310

Butler, R. (1992). Alternative tourism: The end of the wedge. In: Smith, V. L., \& Eadington, W. R. Eds: Tourism alternatives: Potentials and problems in the development of tourism. University of Pennsylvania.

CIA. (2013). Samoa. Retrieved from https://www.cia.gov/library/publications/the-worldfactbook/geos/ws.html

Clancy, M. J. (1999). Tourism and development: Evidence from Mexico. Annals of Tourism Research, 26(1), 1-20.

Cohen, E. (1972). Toward a sociology of international tourism. Social Research, 39(1), 164182.

Cowen, M. \& Shenton, R. (1995). The invention of development. In Crush, J. (Ed.). Power of Development. New York, NY: Routledge.

Cukier, J. (2002). Tourism employment issues in developing countries: Examples from Indonesia. In Sharpley, R. \& Telfer, D. J. (Eds.). Tourism and development: Concepts and issues. Clevedon: Channel View Publications.

Fiske, A. P.(2002). Using individualism and collectivism to compare cultures: A critique of the validity and measurement of the constructs. University of California, Los Angeles.

Hall, C. M. (1994). Tourism and politics: Policy, power, and place. Wiley.

Harrison, D. (1997). Globalisation and tourism: Some themes from Fiji. Pacific Rim Tourism, 167-183.

Hartley, J. F. (2011). The impact of unemployment upon the self-esteem of managers. Journal of Occupational Psychology, 53(2), 147-155.

Hitchcock, M., King, V. T. \& Parnwell, M. J. G. (1993). Tourism in south-east Asia. London: Routledge. 
Index Mundi. (2010). Samoa - International tourism. Retrieved from http://www.indexmundi.com/facts/samoa/international-tourism

International Institute for Sustainable Development. (2011). IISD champions sustainable development around the world through innovation, partnerships, research and communications. Retrieved from http://www.iisd.org/

Islands Business. (2006, December 8). Safe and stable image luring tourists. Retrieved from http://www.islandsbusiness.com/news/index_dynamic/containerNameToReplace=Mi ddleMiddle/focusModuleID=130/focusContentID=7185/tableName=mediaRelease/ov erideSkinName=newsArticle-full.tpl

Jafari, J. (2001). The scientification of tourism. In Smith, V. \& Brent, M. (Eds). Hosts \& guests revisited: Tourism issues of the $21^{\text {st }}$ century. Cognisant Communications Corporation

Jones, M. (1991) FaaSamoa: Implications for Tourism Development in Western Samoa. University of Auckland.

de Kadt, E. (1992). Making the alternative sustainable: Lessons from development for tourism. In: Smith, V. L., \& Eadington, W. R. Eds: Tourism alternatives: Potentials and problems in the development of tourism. University of Pennsylvania.

Kandari, O. P. \& Chandra, A. (2004). Tourism, biodiversity and sustainable development. India: Isha Books.

Lea, J. (1988). Tourism and development in the third world. Routledge.

Liu, A. \& Wall, G. (2006), Planning tourism employment: A developing country perspective. Tourism Management, Volume 27, Issue 1 Pages 159-170

Mihalic, T. (2002). Tourism and economic development issues. In Sharpley, R. \& Telfer, D. (Eds.), Tourism and development, concepts and issues. Clevedon: Channel View Publications. 
Miller, F. (2007). Ecotourism projects in Norway: Some examples for cold climates in “Global Ecotourism Conference”, Norway, 14 - 16 May.

Milne, S. (1990). The impact of tourism development in small Pacific island states: An overview. New Zealand Journal of Geography, 89(1), 16-21.

Milne, S. (2005). The training needs of South Pacific tourism SME owners and managers. SPTO.

Ministry of Natural Resources and the Environment. (2008). Land titles registration. Retrieved from http://www.mnre.gov.ws/documents/legislations/Land\%20Titles\%20Registration\%20 Act\%202008.pdf

MWCSD. (2008). Ministry of women, community and social development (MWCSD): Corporate plan 2008-2012. Retrieved from http://www.mwcsd.gov.ws/images/stories/PUBLICATIONS\%20WEBSITE/Old/Mini stry\%20Published\%20Documents/Corporate\%20Plan\%20English\%20version.pdf

Overton, J. \& Scheyvens, R. (Eds.) (1999). Strategies for sustainable development: Experiences from the Pacific. Zed books.

Page, S. (1999). Tourism and Development: The evidence from Mauritius, South Africa and Zimbabwe. ODI, London.

Page, S. \& Lawton, G. (1996). The Pacific Islands: Markets, development and planning issues. Tourism in the Pacific: Issues and Cases International. Thomson Business Press.

Park, K. (2003). Beach Fale: Indigenous Initiatives in Tourism and Development in Samoa. Master's Thesis, University of Auckland.

Parnwell, M. J. G. (1998). Tourism, globalisation and critical security in Myanmar and Thailand. Singapore Journal of Tropical Geography, 19(2), 212-231. 
Pearce, D. G. (1992). Alternative tourism: Concepts, classifications, and questions. In: Smith, V. L., \& Eadington, W. R. Eds: Tourism alternatives: Potentials and problems in the development of tourism. University of Pennsylvania.

Pearce, D. G. (2002). Samoa tourism development plan, 2002-2006: A focused future for tourism in Samoa.

Ranck, S. (1987). An attempt at autonomous development: The case of the Tufi guest houses, Papua New Guinea. Ambiguous Alternative Tourism in Small Developing Countries: 154-166.

Rosling, H. (2009). Hans Rosling. Significance, 6(4), 179-181.

Sachs, W. (Ed.) (1992). The development dictionary: A guide to knowledge as power. London: Zed Books.

Samoan Sensation. (1998). Introduction. Retrieved from http://www.samoa.co.uk/climate.html

Samoa Tourism Authority. (2009). Samoa tourism development plan: 2009-2013. Retrieved from http://www.sprep.org/att/IRC/eCOPIES/Countries/Samoa/179.pdf

Scheyvens, R. (2002). Tourism for development: Empowering communities. Prentice Hall

Scheyvens. R. (2005). Beach Fale tourism in Samoa: The value of indigenous ownership and control over tourism. CIGAD Working Paper Series.

Scheyvens, R. \& Purdie, N. (1999). Ecotourism. In Overton, J. \& Scheyvens, R. (Eds.) Strategies for sustainable development: Experiences from the Pacific. Zed Books.

Sharpley, R. \& Telfer, D. (Eds.) (2002). Tourism and development, concepts and issues. Channel View Publications

Smith, V. \& Eadington, W. (1992). Tourism alternatives: Potential and problems in the development of tourism. University of Pennsylvania 
Sofied, T. (2003). Empowerment for sustainable tourism development. Emerald Publishing Group Ltd.

Stanley, D. (2000). South Pacific handbook. $7^{\text {th }}$ ed. Emeryville, CA: Avalon Travel Publishing.

Taylor, A. (1999). Issues in maintaining sustainable demand and occupancy in the development of new regional cultural centres. Queensland University of Technology.

The Economist. (2008). Asia, beware Benidorm. Retrieved from http://www.economist.com/node/11376167

The Economist. (2009). Triple bottom line. Retrieved from http://www.economist.com/node/14301663

Therous, P. (1992). The happy isles of Oceania: Paddling the Pacific. Penguin Books. Thomlinson, E. \& Getz, D. (1996). The question of scale in ecotourism: Case study of two small ecotour operators in the Mundo Maya region of Central America. Journal of Sustainable Tourism, 4(4), 52-68.

Timothy, D. J. (2002). Tourism and community development issues. In Sharpley, R. \& Telfer, D. J. (Eds.). Tourism and development: Concepts and issues. Clevedon: Channel View Publications.

Todaro, M. (2000). Economic development. Reading, MA: Addison-Wesley.

Tupufia, L. T. \& Hazelman, N. M. (2012). Govt defends land lease proposal. Retrieved from http://www.samoaobserver.ws/other/ernment-/1887-govt-defends-land-lease-proposal

UNCTAD Secretary General. (2007). 2007 UNCTAD report on Least Developed Countries, United Nations.

UNEP. (1998). Agenda 21, chapter 17. Retrieved from http://islands.unep.ch/da21c17g.htm 
UNWTO. (2004). Indicators of sustainable development for tourism destinations: A guidebook. Retrieved from http://www.iittm.org/doc/Indicators-of-SustainableDevelopment-for-Tourism-Destinations-A-Guide-Book-by-UNWTO.pdf UNWTO. (2008). UNWTO tourism highlights. 2008 edition. Retrieved from http://www.hospitalitynet.org/file/152003629.pdf

U.S. Department of State. (2011). Samoa. Retrieved from http://www.state.gov/outofdate/bgn/samoa/183063.htm

Van der Hoeven, R. (1980). Employment, basic needs and industrialisation: Some reflections on the Lima target. International Labour Review, 119(4), 439.

Weaver, D. (2006). Sustainable tourism: Theory and practice. Elsevier.

World Tourism Organization . (2004). Making tourism work for small island developing states. World Tourism Organisation. 
Appendix: Information Sheet, Questionnaire and Map of Samoa 


\section{The Value of Large Scale Tourism Ventures in Samoa}

Researcher: Donald Park, Candidate for a Master's of Development Studies, Victoria University of Wellington.

I am a Master's Student in Development Studies at Victoria University of Wellington. As part of the degree I am undertaking a research project leading to a thesis.

The aim of the study is to ascertain the benefits or otherwise of large scale tourism ventures in Samoa. The attached interview will take about 20 minutes to complete.

The responses collected will form the basis of my research project and put into a written report for publication into the University Library. The responses collected will not be anonymous unless the participant expressly wishes this to be so. If you wish your responses to remain anonymous, you may choose to leave the any of the identifying fields blank.

For further information I can be contacted at donaldpark@ hotmail.com. My supervisor, Professor John Overton can be contacted at John.Overton@vuw.ac.nz or Victoria University PO Box 600, Wellington, New Zealand 


\section{Tourism Development Questionnaire}

Occupation:

Previous Occupation prior to your involvement with Aggie Greys.:

Gender:

Role at village level:

Age:

Due to links with Aggie Greys Lagoon Beach and Spa Resort, how has your communities' standard of living (food, clothing, shelter) been altered (Please Circle)

\begin{tabular}{|c|c|c|c|c|c|c|}
\hline Significantly & Moderately & Slightly & Neutral & Slightly & Moderately & Significantly \\
\hline Vorse & Worse & Worse & & Better & Better & Better \\
\hline
\end{tabular}

Please explain how

Due to links with Aggie Greys Lagoon Beach and Spa Resort, how have your communities' $\underline{\text { sense of esteem been altered (Please Circle) }}$

\begin{tabular}{|c|c|c|c|c|c|c|}
\hline Significantly & Moderately & Slightly & Neutral & Slightly & Moderately & Significantly \\
\hline Worse & Worse & Worse & & Better & Better & Better \\
\hline
\end{tabular}

Please explain how 
Due to links with Aggie Greys Lagoon Beach and Spa Resort, how have your communities' opportunities been altered (Please Circle)

\begin{tabular}{|c|c|c|c|c|c|c|}
\hline Significantly & Moderately & Slightly & Neutral & Slightly & Moderately & Significantly \\
\hline Worse & Worse & Worse & & Better & Better & Better \\
\hline
\end{tabular}

Please explain how

Due to links with Aggie Greys Lagoon Beach and Spa Resort, how have women in your community fared in respect to the above (Please Circle)

\begin{tabular}{|c|c|c|c|c|c|c|}
\hline Significantly & Moderately & Slightly & Neutral & Slightly & Moderately & Significantly \\
\hline Worse & Worse & Worse & & Better & Better & Better \\
\hline
\end{tabular}

Please explain how 
Open ended questions:

What do you think about large tourism in your community?

Has large tourism threatened your tradition and values? If so, how?

Has large tourism threatened your environment? If so, how?

What changes would you like to see to large tourism?

Name: (Optional)

Would you be willing to take follow up questions? Yes/No

If yes, please provide additional contact details 


\section{Consent Form}

\section{Evaluation of the government's tourism investment strategy in Samoa}

I have been given and understood an explanation of this research project. I have had an opportunity to ask questions and have them answered to my satisfaction. I understand that I may withdraw myself or any information provided from this project (before data collection and analysis is complete) at any time.

I understand that the research by default is not anonymous and that opinions and information may be attributed back to your identifying characteristics. If you do not wish this to happen please circle "no" below and anything you write will remain without identifiers.

Approval for attribution of opinions and information:

Yes / No (Please circle )

Signed:

Date:

Name 
Map of Samoa

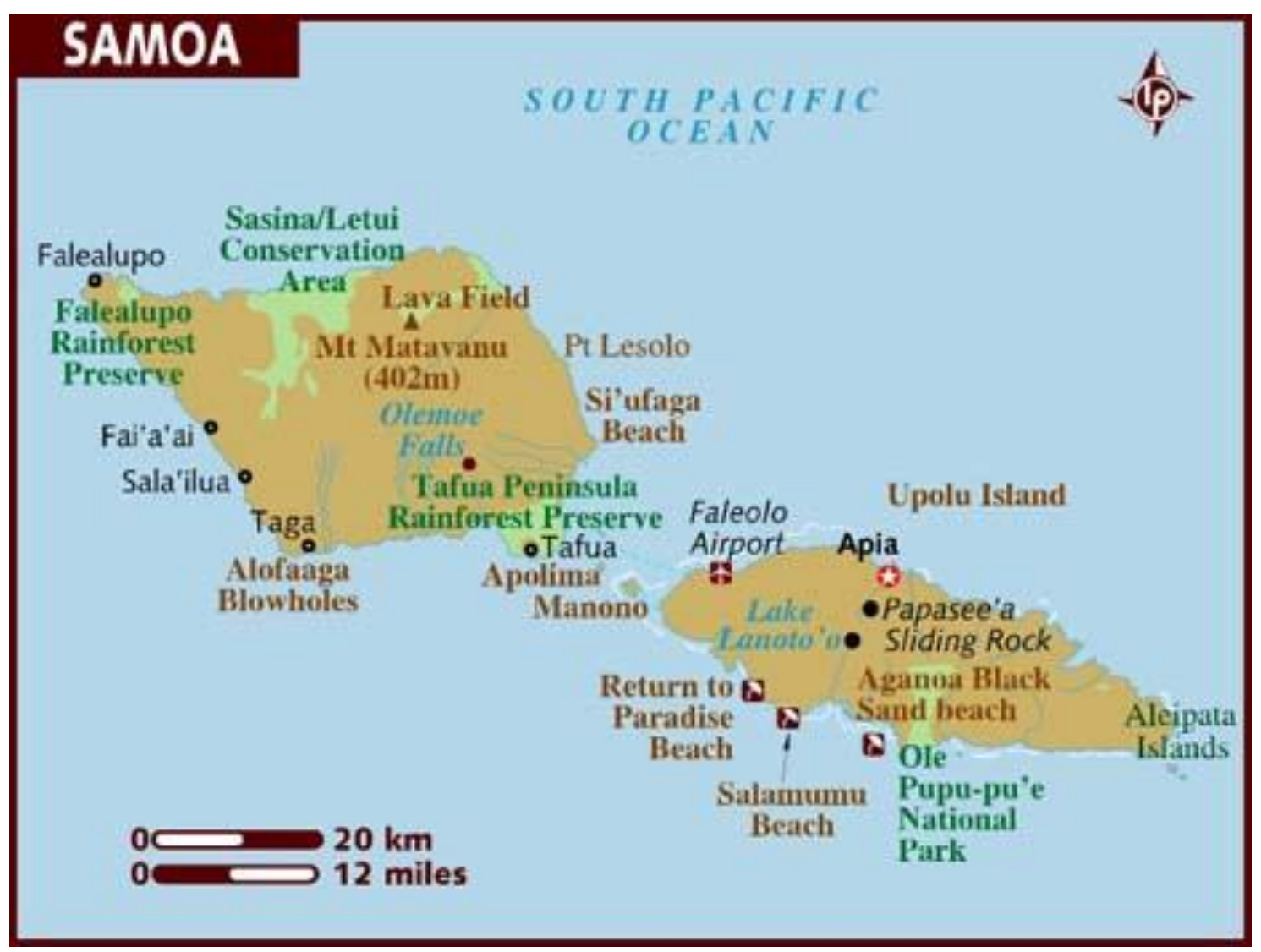

